\title{
POSSÍVEIS ESTRATÉGIAS PARA PREVENÇÃO DE OTITE MÉDIA AGUDA: ESTUDO IN VITRO DA LIBERAÇÃO DE XILITOL EM SALIVA ARTIFICIAL APÓS APLICAÇÃO DE VERNIZ EM DIFERENTES CONCENTRAÇÕES
}

\section{AGNES DE FÁTIMA FAUSTINO PEREIRA}

Dissertação apresentada à Faculdade de Odontologia de Bauru da Universidade de São Paulo, como parte dos requisitos para obtenção do título de Mestre em Odontologia, área de Saúde Coletiva. 


\section{POSSÍVEIS ESTRATÉGIAS PARA PREVENÇÃO DE OTITE MÉDIA AGUDA: ESTUDO IN VITRO DA LIBERAÇÃO DE XILITOL EM SALIVA ARTIFICIAL APÓS APLICAÇÃO DE VERNIZ EM DIFERENTES CONCENTRAÇÕES}

Dissertação apresentada à Faculdade de Odontologia de Bauru da Universidade de São Paulo, como parte dos requisitos para obtenção do título de Mestre em Odontologia.

Área de Concentração: Saúde Coletiva Orientadora: Profa ${ }^{\mathrm{Dr}}{ }^{\mathrm{a}}$ Magali de Lourdes Caldana 


\begin{tabular}{|c|}
\hline Pereira, Agnes de Fátima Faustino \\
P414p Possíveis estratégias para a prevenção de otite \\
média aguda: estudo in vitro da liberação de xilitol em \\
saliva artificial após aplicação de verniz em diferentes \\
concentrações/Agnes de Fátima Faustino Pereira. - \\
Bauru, 2007. \\
$\quad 87$ p.: il.; $30 \mathrm{~cm}$. \\
Dissertação. (Mestrado) - Faculdade de Odontologia de \\
Bauru. Universidade de São Paulo \\
Orientadora: $\operatorname{Prof}^{\mathrm{a}} \operatorname{Dr}^{\mathrm{a}}$ Magali de Lourdes Caldana \\
\end{tabular}

Autorizo, exclusivamente para fins acadêmicos e científicos, a reprodução total ou parcial desta dissertação/tese, por processos fotocopiadores elou meios eletrônicos.

Assinatura do autor:

Data: I 


\section{AGSES DE FÁTIMA FAUSTINO PEREIRA}

\section{Dados Curriculares}

04 de outubro de 1980

Bauru - SP

Filiação

$2000-2003$

$2004-2005$

$2005-2007$

Associações
Nascimento

Ondina de Fátima Faustino Pereira Lineu Pereira

Curso de Graduação em Fonoaudiologia pela Faculdade de Odontologia de Bauru - Universidade de São Paulo

Fonoaudióloga Clínica do Ambulatório de Diagnóstico e Reabilitação Audiológica (ADRA)

Curso de Pós-Graduação em Odontologia, área de Saúde Coletiva, nível Mestrado - Faculdade de Odontologia de Bauru - Universidade de São Paulo

- Sociedade Brasileira de Fonoaudiologia - SBFa

- CRFa - SP - Conselho Regional de Fonoaudiologia 


\section{DEDICATÓRIA}

À minha querida mãe, Ondina, e ao meu querido irmão, Hermes, pelo apoio, amor, dedicação, ensinamento e estímulo dispensados em todos os momentos da minha vida.

Ao meu amado Thiago, o qual serei eternamente grata por seu constante incentivo, companheirismo e compreensão durante todos os momentos que compartilhamos.

\section{A vocês,}

Preciosos tesouros da minha vida, Dedico este trabalho! 
"E nunca te desesperes Pois quem tem fé Tem poderes E não fica ao desabrigo... Quem ama mais Que é amado, Tem sempre, sempre, Ao seu lado V'a mão, um rosto amigo..." 


\section{AGRADECIMESTOS}

À Deus, fonte de toda sabedoria, por me mostrar a cada dia que com ELE tudo é possível.

À minha orientadora, Prof ${ }^{a}$ Dr $^{a}$ Magali de Lourdes Caldana, pelo acompanhamento, orientação, confiança e pelas palavras de carinho e incentivo a mim dedicados. Seus preciosos ensinamentos desde a época da graduação permeiam e enriquecem minha vida profissional. Muito obrigada!

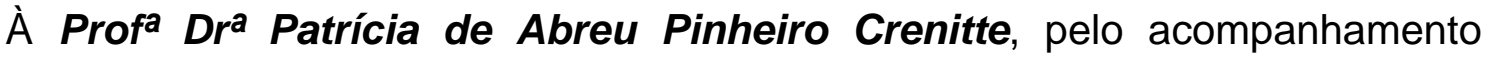
durante minha formação acadêmica, pelo carinho, disponibilidade, sugestões e pelo enorme prazer de sua presença no exame de qualificação.

Ao Prof. Dr. José Roberto de Magalhães Bastos, pelos brilhantes ensinamentos e constante incentivo no estudo do xilitol.

Ao Prof. Dr. Kauko Makinen, Universidade de Turku/Finlândia, pela valiosa contribuição prestada no início deste trabalho.

Aos professores e funcionários do Departamento de Odontopediatria, Ortodontia e Saúde Coletiva, pela amizade e pela convivência agradável e construtiva. 
Aos professores do Curso de Fonoaudiologia da Faculdade de Odontologia de Bauru, pela valiosa contribuição na minha formação acadêmica. Em especial, à Prof ${ }^{a} D r^{a}$ Giedre Berretin-Felix, pelo constante incentivo durante minha graduação pela área de saúde coletiva.

À Faculdade de Odontologia de Bauru - USP, na pessoa do senhor diretor, Prof. Dr. Luiz Fernando Pegoraro, e da senhora coordenadora de pósgraduação, Prof $^{a}$ Dr $^{a}$ Maria Aparecida de Andrade Moreira Machado.

A Pós Graduação da FOB/USP e seus funcionários, pela responsabilidade, apoio e cuidado que sempre dedicaram aos alunos.

Aos funcionários do Laboratório de Bioquímica, Telma e Ovídio, pelo carinho e valiosa contribuição na execução deste trabalho. Vocês foram maravilhosos!

Ao Prof. Dr. José Roberto Pereira Lauris pela disponibilidade e atenção dispensada à execução da análise estatística deste trabalho.

Aos meus amigos da XI Turma de Fonoaudiologia FOB/USP e Turma de Mestrado/2005 FOB/USP pela amizade e pelas lições que trocamos ao longo desta nossa jornada.

Aos amigos do Laboratório de Bioquímica, Juliano Pessan, Carol Magalhães, Thiemi, Flavinha, Flávia, Prof. Rodrigo, Irene, Tatiana, Heloisa, 
pela amizade e pelas discussões que contribuíram no enriquecimento deste trabalho.

Aos amigos Gislaine, Sushila, Juliana Julianelli, Josana, Ricardo Henrique (Napão), Carina, Fabiana Pedrosa, Marcelo Neves (Diastema), Eduardo (Noel), Danilo, Sophia, Estela, Fernanda Franco, Fernanda Menechino, Patricia, Érica, Michele, pelo saudável convívio e amizade! Tenho carinho especial por todos vocês!

Ao Ambulatório de Diagnóstico e Reabilitação Audiológica (ADRA) pela oportunidade e preciosa contribuição na minha atuação profissional.

À fonoaudióloga Janaina Trovarelli, pela preciosa amizade e pelos momentos agradáveis de convívio. Trabalhar com você foi um grande aprendizado técnico, ético e humano. Você é única!

À minha segunda família, João, Maria Isabel e Diogo, que sempre foram muito carinhosos e acolhedores durante todo o nosso convívio. Registro aqui toda a minha admiração e respeito pessoal e profissional que tenho por vocês.

Aos meus avós "adotivos", Sra. Neusa e Sr. Edson, por todos os momentos agradáveis que passamos juntos e pelas palavras de carinho, admiração e motivação que permearam as nossas conversas. Vocês são adoráveis! 
Ao amigo e poeta, Alfredo Brasílio de Araújo/Hominho, pelos momentos descontraídos nos quais me "ensinou" a dançar e pelo enorme prazer de ter um trecho de suas adoráveis poesias em minha dissertação.

À pedagoga e amiga, Francisca Paula, pelo carinho e agradáveis conversas que enriqueceram ainda mais a minha prática profissional.

À DANISCO BRASIL LTDA, pela contribuição no fornecimento de xilitol.

À indústria FGM/Brasil, pela contribuição na formulação dos vernizes com xilitol.

À Coordenadoria de Aperfeiçoamento de Pessoal de Nível Superior (CAPES) pela bolsa de estudos concedida.

A todos aqueles que, direta ou indiretamente, contribuíram para este trabalho.

Muito Obrigada !!! 


\section{SUMÁRIO}

RESUMO

xiii

1 INTRODUÇÃO

3

2 REVISÃO DE LITERATURA ............................................................ 9

2.1 Otite Média Aguda............................................................................... 9

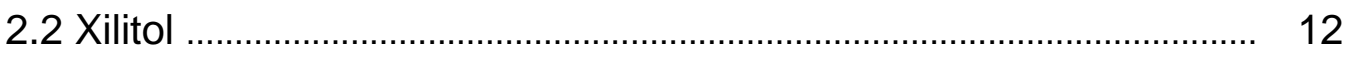

2.2.1 Xilitol na prevenção de cárie dentária ........................................... 13

2.2.2 Xilitol na prevenção de otite média aguda ................................... 16

2.2.3 Desvantagens do xilitol ................................................................. 22

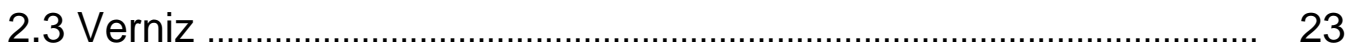

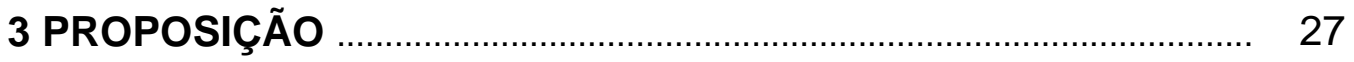

4 MATERIAL E MÉTODOS ................................................................ 31

4.1 Delineamento experimental........................................................ 31

4.2 Obtenção dos dentes bovinos........................................................ 32

4.3 Elaboração do verniz ................................................................... 33

4.4 Aplicação do verniz....................................................................... 35

4.5 Tempos de coleta da saliva ............................................................ 37

4.6 Análise das amostras.......................................................................... 39

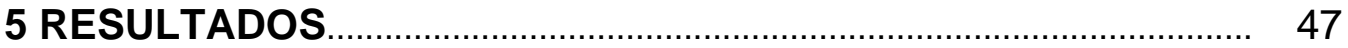

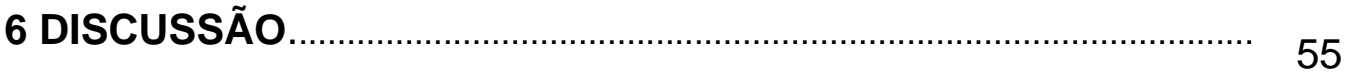

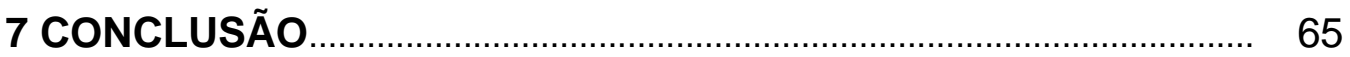

8 ANEXOS

9 REFERÊNCIAS BIBLIOGRÁFICAS ................................................ 77

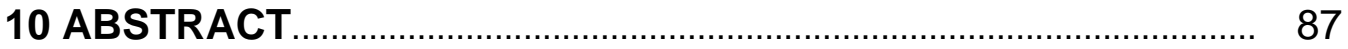


Resumo 


\section{RESUMO}

Este estudo teve como objetivo verificar a liberação de xilitol em saliva artificial ao longo do tempo após aplicação de verniz contendo 10\% e 20\% do açúcar. Para tal, 15 blocos de dentes bovinos foram divididos em três grupos (Grupo 1- recebeu verniz a 10\%; Grupo 2 - recebeu verniz a 20\% e Grupo 3 recebeu verniz sem xilitol). Na seqüência, cada bloco foi imerso em tubo de microcentrífuga contendo $500 \mu \mathrm{L}$ de saliva artificial. Foram coletadas e analisadas as amostras salivares em diferentes tempos após a aplicação do verniz (1h, 8h, 12h, 16h, 24h, 48h e 72h). Comparando-se os valores de concentração de xilitol em mg/L nos grupos $\mathrm{G} 1$ e $\mathrm{G} 2$, pode-se observar que houve diferença estatisticamente significante entre os grupos (ANOVA, $F=32,68, p=0,0004$ ) e tempos (ANOVA, $F=2465,53, p=0,0000$ ). Foi observada interação entre as variáveis grupo e tempo (ANOVA, $F=1486,25, p=0,0000$ ). Notou-se uma liberação significativamente maior no Grupo G2 nos tempos de 1 h (168,96 mg/L) e 8 h (164,22 mg/L), quando comparados com o Grupo G1 (1 $\mathrm{h}=63,42 \mathrm{mg} / \mathrm{L}$ e $8 \mathrm{~h}=69,52 \mathrm{mg} / \mathrm{L})$, conforme detectado pelo teste de Tukey $(p=0,0002)$. No entanto, nos tempos de 12 h, 16 h, 24 h, 48 h e 72 h, a liberação do açúcar foi significativamente maior no Grupo 1 (56,92 mg/L; 49,70 mg/L; 49,40 mg/L; 55,52 mg/L; 32,66 mg/L, respectivamente) em relação ao Grupo 2 (29,90 mg/L; 18,52 mg/L; 19,76 mg/L; 24,20 mg/L; 12,72 mg/L, respectivamente), conforme detectado pelo teste de Tukey $(p=0,0002)$. Portanto, o verniz contendo $10 \%$ de xilitol liberou maiores concentrações do açúcar em períodos de tempo mais longos, denotando-se em uma liberação mais lenta e homogênea deste verniz. 
Palavras-chave: xilitol - prevenção - otite média aguda - crianças 
1 Introdução 


\section{INTRODUÇÃO}

A otite média $(\mathrm{OM})$ é uma das doenças infantis mais comuns e de maior morbidade principalmente em crianças com idade inferior a três anos (GOLZ et al., ${ }^{24} 2005$, CRIPPS et al., $\left.{ }^{13} 2005\right)$. Trata-se de uma inflamação da mucosa que reveste a cavidade timpânica, que pode ser de causa infecciosa ou bacteriana. Estudos epidemiológicos mostraram que durante a década de 1990 houve um aumento significativo na prevalência de otite média em crianças e elevada recorrência destes episódios em bebês com até um ano de idade (PELTON, ${ }^{56}$ 2000).

A prevalência de otite média também é alta em crianças que estão começando sua vida escolar, por volta dos seis anos de idade. Existe uma grande preocupação quanto aos episódios e recorrências dessa doença nessa faixa etária. Trata-se de um período crítico onde a criança necessita da integridade auditiva para o desenvolvimento adequado da linguagem oral e escrita (GOLZ et al., ${ }^{24}$ 2005, LUBIANCA;HEMB;SILVA, ${ }^{39} 2006$ ).

O tratamento mais comum nos casos de otite média é a terapia com antibióticos. No entanto, existem muitas discussões quanto à prescrição desses medicamentos. Como escrito anteriormente, a criança pode experienciar vários episódios da doença durante sua infância. Dessa forma, os antibióticos são extensamente utilizados podendo proporcionar um aumento da resistência das bactérias patogênicas (PELTON, ${ }^{56}$ 2000, CRIPPS et al., ${ }^{13} 2005$, BLOMGREN; PITKARANTA, ${ }^{10}$ 2005).

A preocupação quanto à seleção dessas bactérias e a importância de um trabalho preventivo e não apenas curativo direcionaram estudos com o 
objetivo de desenvolver outras estratégias diferentes do uso de antibióticos, dentre eles o xilitol (KONTIOKARI et al., ${ }^{36} 1995$, UHARI et al., ${ }^{75} 1996$, UHARI et al., $\left.{ }^{76} 1998\right)$.

O xilitol é um carboidrato polissacarídeo que está presente em muitas frutas e é utilizado como adoçante principalmente em gomas de mascar (TAPIAINEN et al., ${ }^{69}$ 2002). Estudos relatam que o xilitol pode ter inúmeras aplicações médicas, dentre elas: prevenção de cárie dentária e otite média aguda (MAKINEN, ${ }^{48}$ 2000).

A descoberta do benefício do xilitol na prevenção de otite média aguda deu-se a partir de estudos comparativos na área odontológica. Os resultados obtidos acerca dos efeitos anticariogênicos produzidos por esse açúcar incentivaram pesquisas que esclarecessem a ação do carboidrato sobre outras bactérias orais, dentre elas, as otopatogências (MAKINEN, ${ }^{47}$ 2000).

O primeiro estudo "in vitro" realizado com a finalidade de verificar a influência do xilitol sobre o crescimento dos patógenos responsáveis pela otite média aguda deu-se em 1995 por KONTIOKARI et al. ${ }^{36}$ Os autores verificaram a inibição do crescimento de Streptococcus pneumoniae na presença de xilitol, inferindo que a sua administração poderia interferir sobre a doença, estimulando novos estudos.

Estudos clínicos aleatórios realizados na Finlândia também concluíram que o xilitol contribui na diminuição da incidência de otite média aguda. Porém, esse carboidrato foi administrado através da utilização de gomas de mascar já comercializadas naquele país. Devido a incidência de otite média ser maior nos dois primeiros anos de vida, métodos de administração 
mais adequados devem ser encontrados para que os bebês tenham melhor acesso aos benefícios deste açúcar.

Portanto, o presente trabalho tem como objetivo elaborar um verniz contendo xilitol e estudar a liberação do açúcar em saliva artificial em diferentes tempos considerando ser esta uma estratégia de administração possivelmente eficaz em crianças menores que não se beneficiam adequadamente das gomas de mascar. Além disso, o verniz poderá ser capaz de promover a liberação lenta do xilitol, o que provavelmente contribuirá na manutenção das concentrações salivares adequadas para a obtenção do desejado efeito antimicrobiano. 
2 Revisão de Literatura 


\section{REVISÃO DE LITERATURA}

\subsection{OTITE MÉDIA AGUDA}

A otite média é a causa mais comum de atendimento médico infantil em vários países, correspondendo a um terço das consultas pediátricas e de 25 a $40 \%$ das prescrições de antibióticos (LANPHEAR et al., ${ }^{38}$ 1997, JOKIERKKILA et al., ${ }^{32}$ 1998, FRIED et al., ${ }^{20}$ 1998, ESKOLA; KILPI, ${ }^{19} 2000$; GONZÁLES, ${ }^{26}$ 2001; ROVERS et al., ${ }^{58}$ 2004). Estima-se que o custo anual gasto para seu tratamento é de aproximadamente 138 milhões de dólares na Finlândia e por volta de 3 bilhões nos Estados Unidos (GATES, ${ }^{21}$ 1996, KAPLAN et al., ${ }^{34}$ 1997, NIEMELA et al,. ${ }^{52}$ 1999, ALSARRAF;GATES, ${ }^{3}$ 1999). Trata-se de uma doença altamente prevalente na infância, com o maior pico de incidência entre 6 e 24 meses de idade, e com segundo pico de incidência entre 4 e 7 anos de idade (PARADISE et al., ${ }^{54} 1997$, PELTON, ${ }^{56} 2000$, GOLZ et al., ${ }^{24}$ 2005). Estes fatos contribuem para a otite ser um problema de grande relevância para a saúde pública, pois a doença tem um grande impacto na criança, na família e no sistema de assistência médica.

A otite média aguda (OMA) é uma seqüela de infecção das vias aéreas superiores que se propaga à mucosa da orelha média pela tuba auditiva (KATZ, ${ }^{35}$ 1999, SIH, ${ }^{64} 2003$, ROVERS et al., ${ }^{58}$ 2004). É caracterizada por uma inflamação que se apresenta com início súbito e acompanhado por otalgia, vermelhidão da membrana timpânica e febre (GATES et al., ${ }^{22} 2002$, SIH $^{64}$ 2003). Outros sintomas também podem ser observados, como cefaléia, vômitos, irritabilidade e diminuição da acuidade auditiva (ALMEIDA; ALMEIDA ${ }^{2}$, 
2003). Recidivas freqüentes de OMA são definidas por otite média aguda recorrente (OMAR). A Sociedade Brasileira de Otorrinolaringologia ${ }^{66}$, 2001, descreve esse quadro quando há 3 episódios de OMA num período de seis meses ou quatro episódios num período de doze meses.

A patogênese da otite média é multifatorial (GATES et al., ${ }^{22} 2002$, MARONE e LORENZI, ${ }^{49}$ 2003, ROVERS et al., ${ }^{58}$ 2004). $\mathrm{SIH}^{64}, 2003$, cita as disfunções tubárias e os agentes infecciosos microbianos como os fatores etiológicos mais importantes na doença.

A tuba auditiva (TA) é um tubo osteocartilaginosos que comunica a orelha média com a nasofaringe. Suas funções mais importantes compreendem os mecanismos de proteção, drenagem e ventilação do espaço da orelha média. Quando há um mau funcionamento da TA, o ar aprisionado na cavidade da orelha média é absorvido pelo seu revestimento mucoso, criando uma pressão negativa na orelha média e, por fim, a transudação de líquido para dentro da cavidade (NORTHERN; DOWNS, ${ }^{53}$ 2002). Assim, obstruções tubárias contribuem para o aparecimento de sintomas otológicos.

Infecções de vias aéreas superiores e a fenda palatina são alguns dos fatores que predispõem a um inadequado funcionamento da tuba auditiva (MARONE; LORENZII, ${ }^{49}$ 2003). As infecções, principalmente envolvendo as tonsilas e adenóides, podem afetar estruturas próximas e/ou criar bloqueio em torno da abertura da tuba auditiva (NORTHERN; DOWNS, ${ }^{53}$ 2002). A congestão observada na região da TA pode gerar sua obstrução, com desenvolvimento de pressão negativa na orelha média que, quando prolongada, pode levar a 'aspiração' de microorganismos patogênicos. Em virtude da obstrução tubária presente, há comprometimento da função de 
drenagem da orelha média, com acúmulo de líquido em sua cavidade, resultando em quadro de OMA (MILLER; GIANOLI, ${ }^{50}$ 1996, MARONE; LORENZI ${ }^{49}$ 2003). Nos casos de fenda palatina, justifica-se a insuficiência dos mecanismos de abertura da TA decorrente de alterações da anatomia da musculatura tubária (PARADISE, ${ }^{55}$ 1997, $\mathrm{SIH}^{64}$ 2003).

Quanto aos agentes infecciosos, a otite média aguda pode ser causada por vírus ou bactéria, porém os microorganismos mais freqüentes são os de origem bacteriana: Streptococcus pneumoniae (40-50\% das ocorrências); Haemophylus influenzae (20-30\%) e Moraxella catarrhalis (10-15\%) (GONZÁLES, ${ }^{26}$ 2001; ROVERS et al., $\left.{ }^{58} 2004, \mathrm{SIH}^{64} 2005\right)$.

Por ser predominantemente de origem bacteriana, o tratamento mais comum nos casos de otite média aguda é a antibioticoterapia (Sociedade Brasileira de Otorrinolaringologia, ${ }^{66}$ 2001; ROVERS et al. ${ }^{58}$, 2004; ALMEIDA; ALMEIDA $^{2}$, 2005). Estudos têm relatado grande preocupação quanto à administração desses medicamentos, pois as bactérias têm uma notável capacidade de desenvolver resistência aos antibióticos (PARADISE, ${ }^{54} 1997$, DAGAN et al., ${ }^{15}$ 2001, ROVERS et al., ${ }^{58}$ 2004). Pneumococo resistente a antibióticos são difícieis de erradicar da orelha média e da nasofaringe. Nesses casos os antibióticos não somente falham em promover a erradicação bacteriológica residentes na nasofaringe, como também podem, muitas vezes, induzir à superinfecção no fluído da orelha média (DAGAN et al., ${ }^{15}$ 2001).

Além da resistência bacteriana, há preocupação com as complicações que a otite média pode acarretar no indivíduo. Sabe-se que as variações clínicas da otite média formam um contínuo de processo patológico e estão dinamicamente inter-relacionadas (NORTHERN; DOWNS, ${ }^{53}$ 2002). 
Assim, as formas iniciais simples de otite média, se não tratadas ou tratadas inadequadamente, podem levar a processos patológicos mais complexos e graves tais como: timpanosclerose, perfuração da membrana timpânica, labirintite, paralisia facial, abcesso cerebral, meningite, perda auditiva sensorioneural. Além do mais, a otite média recorrente em uma fase precoce da vida pode prejudicar o desempenho da capacidade cognitiva das crianças e influenciar negativamente na aquisição e desenvolvimento da linguagem oral e escrita (SANTOS, ${ }^{59}$ 1996, PARADISE et al., ${ }^{54}$ 1997, PELTON, ${ }^{56} 2000$, NORTHERN; DOWNS, ${ }^{53} 2002$, GOLZ et al., $\left.{ }^{24} 2005\right)$.

Diante de todas estas problemáticas que envolvem a otite média, estudos estão sendo direcionados com o intuito de encontrar soluções preventivas e não apenas curativas. Dentre as formas preventivas investigadas, encontra-se o xilitol.

\subsection{XILITOL}

O xilitol é um carboidrato naturalmente encontrado em diversas frutas e vegetais. Com o poder adoçante similar ao açúcar, contendo $40 \%$ calorias menos que a sacarose, é extraído principalmente da Bétula e árvores especiais, próprias de paises escandinavos (TRINDADE, ${ }^{74}$ 2005). Pode também ser produzido industrialmente a partir de sabugo de milho, cana de açúcar, cascas de sementes e de nozes (MAKINEN, ${ }^{48} 2000$, CUNHA $^{14}{ }^{2003) .}$ Atualmente, a produção mundial de xilitol ultrapassa 10.000 toneladas por ano e é direcionada principalmente à confecção de produtos manufaturados, na indústria alimentícia, farmacêutica, cosmética e de higiene oral (MAKINEN, ${ }^{48}$ 2000, TAPIAINEN et al., ${ }^{69} 2002$, LYNCH et al., ${ }^{40}$ 2003). Em produtos de dieta, 
sua adição pode substituir todo ou parte do açúcar contido em balas, doces e gomas de mascar (SINTES et al., $\left.{ }^{65} 2002\right)$.

O nome xilitol relaciona-se à palavra xilose, que é o açúcar da madeira, a partir do qual o xilitol foi obtido pela primeira vez (MAKINEN, ${ }^{47}$ 2000). Na nomenclatura química, o xilitol é classificado similarmente ao sorbitol e ao manitol, ou seja, como um açúcar-álcool ou um poliol.

O xilitol possui inúmeras propriedades, dentre as quais destaca grande potencial de aplicação nas áreas médica e odontológica, tendo-se mostrado eficaz no tratamento de diabetes, desordem no metabolismo de lipídeos, lesões renais e parenterais, prevenção de infecções pulmonares, otites, osteoporose e da cárie dentária (MAKINEN et al., ${ }^{46}$ 1996, MAKINEN, ${ }^{48}$ 2000).

\subsubsection{Xilitol na prevenção de cárie dentária}

A descoberta do xilitol aconteceu em 1890 por um químico alemão chamado Emil Herman Fischer e por seu assistente Rudolf Stahel. Embora Dr. Fischer tenha recebido o Prêmio Nobel por suas realizações no âmbito das ciências químicas, o xilitol recebeu pouca atenção durante esse período (MAKINEN, ${ }^{47}$ 2000).

Estudos relacionados à utilização do xilitol e cárie dentária só tiveram início na década de 70, em Turku, na Finlândia. Conheceu-se, primeiramente, que o xilitol tinha a capacidade de reduzir o crescimento e a produção de ácidos do Streptococcus mutans, principal bactéria responsável pelo 
desenvolvimento da cárie dentária (MAKINEN, ${ }^{43} 1989$, ISOKANGAS et al., ${ }^{29}$ 1993).

A cárie dentária é uma doença infecciosa multifatorial dietadependente atribuída primariamente à presença de bactérias orais e sacarose. A aderência bacteriana parece ser um pré-requisito para a cárie dentária (MAKINEN, ${ }^{44}$ 1993, MAKINEN, ${ }^{45}$ 1996). O mecanismo pelo qual o xilitol interfere na inibição do crescimento dessas bactérias ainda não é totalmente esclarecido (BANOCZY et al., ${ }^{6}$ 1985, SCHEININ et al., ${ }^{63} 1985$, ISOKANGAS et al., ${ }^{30}$ 1993).

Dentre as hipóteses propostas para explicar o efeito do xilitol na redução da incidência da cárie dentária, efeitos específicos no metabolismo e crescimento tem sido considerados. O mecanismo pelo qual o xilitol inibe 0 crescimento e metabolismo bacteriano pode ser parcialmente descrito pelo consumo de fosfoenolpiruvato (PEP), uma vez que o xilitol é transportado via sistema frutose-fosfotransferase (SCHEININ, ${ }^{62}$ 1976, TRAHAN et al., ${ }^{72} 1985$, GONÇALVES, ${ }^{25}$ 2004), resultando em acúmulo intracelular de xilitol-5-fosfato. Este metabólito intermediário não é utilizado, sendo então desfosforilado e expelido do interior celular como xilitol. Este ciclo, conhecido por "ciclo fútil", consome energia e resulta na inibição do crescimento e metabolismo bacteriano. (ASSEV; ROLLA, ${ }^{4}$ 1986, SODERLING et al., ${ }^{67} 1989$, ISOKANGAS et al., ${ }^{31} 2000$, GONÇALVES, ${ }^{25}$ 2004).

Vários estudos randomizados com o objetivo de analisar a influência do xilitol na prevenção de cárie dentária são encontrados na literatura.

Um dos primeiros trabalhos realizados com o xilitol na área odontológica foi o de MOUTON; SCHEININ; MAKINEN, ${ }^{51}$ em 1975, onde 
analisaram o efeito de gomas de mascar contendo xilitol na redução da placa dentária. Para tanto utilizaram uma amostra de 96 sujeitos divididos aleatoriamente em três grupos: 32 utilizaram gomas de mascar com sacarose, 36 utilizaram gomas de mascar com xilitol e 28 não fizeram uso de qualquer goma (grupo controle). Eles foram instruídos a permanecerem por três dias com higiene bucal restrita para permitir a formação da placa dentária. Esta foi a primeira fase do experimento, onde os sujeitos receberam instrução para mascar seis gomas por dia, sendo uma ao acordar, duas após a primeira refeição, duas após a segunda refeição e uma ao deitar. Na segunda fase foi realizado o registro clínico, através da pesagem da placa dentária. $\mathrm{Na}$ avaliação dos registros observaram que o peso da placa dentária, coletado no grupo que utilizou gomas com xilitol foi $24 \%$ menor que no grupo controle e $40 \%$ menor que no grupo que utilizou as gomas contendo sacarose, indicando que o uso de gomas de mascar contendo xilitol promoveu efeitos benéficos na amostra analisada.

No mesmo ano, SHEININ et al. ${ }^{60}$ realizaram um estudo em Turku, que ficou bastante conhecido entre os trabalhos relacionados ao xilitol. Compararam os efeitos de substituição parcial da sacarose por xilitol, clinica e radiograficamente dos incrementos de cárie. A pesquisa contou com a colaboração de adultos jovens que foram divididos aleatoriamente nos grupos S e X. Os voluntários do grupo S foram instruídos a mascar de três a sete gomas contendo sacarose diariamente, enquanto os do grupo $\mathrm{X}$ receberam as mesmas instruções, porém utilizaram gomas adocicadas com xilitol. Inicialmente todos tiveram a alimentação habitual avaliada por cinco dias. Após um ano de pesquisa, tiveram a constatação de que houve uma diferença 
acentuada entre os incrementos de cárie dos dois grupos, sendo que houve indicação clara dos efeitos inibitórios do xilitol como método profilático.

MAKINEN et al., ${ }^{46}$ em 1996, reuniram os resultados obtidos pelo "Programa de Xilitol de Michigan" realizado entre 1986 e 1985 de um programa de prevenção da cárie dentária. O motivo fundamental deste estudo foi evidenciar a teoria "pentitol-hexitol", na prevenção da cárie dentária. Os voluntários foram crianças, inicialmente com seis anos de idade, adultos e idosos, a quem foram dados estimulantes salivares, principalmente gomas de mascar, por períodos de duas semanas a 56 meses. Os autores comprovaram que os resultados do programa proporcionaram outros dados sobre os efeitos anticariogênicos e biológicos bucais dos polióis dietéticos naturais, e sugerem que o uso de gomas de mascar com xilitol ou pastilhas contendo xilitol, pode ser considerado um método adicional muito benéfico na prevenção e estabilização de cáries dentárias em todas as faixas etárias.

HONKALA et al., ${ }^{28}$ 2006, acompanharam as condições bucais de 176 estudantes que faziam uso regular de doces contendo xilitol (3 vezes/dia) durante o período de um ano e seis meses. No final do estudo, os autores observaram que houve uma redução significativa na incidência de cárie, bem como auxiliou na remineralização de manchas brancas. Com estes resultados, concluíram que o uso de xilitol é uma alternativa eficaz na prevenção de cárie dentária. 


\subsubsection{Xilitol na prevenção de otite média aguda}

As descobertas realizadas sobre o efeito anticariogênico produzido pelo xilitol incentivaram pesquisas que esclarecessem a ação do carboidrato sobre outras bactérias orais, dentre elas, as otopatogências (KONTIOKARI et al., ${ }^{36} 1995$, UHARI et al., ${ }^{75} 1996$, UHARI et al., ${ }^{76}$ 1998).

O primeiro estudo realizado com a finalidade de verificar a influência do xilitol sobre o crescimento dos patógenos causadores de OMA deu-se em 1995 por KONTIOKARI et al. ${ }^{36}$ Os autores questionaram se o açúcar poderia afetar outras bactérias presentes na flora da nasofaringe, principalmente àquelas responsáveis pelas infecções respiratórias. O estudo demonstrou a inibição do crescimento do Streptococcus pneumoniae na presença de xilitol em um estudo 'in vitro' adicionando o carboidrato em duas concentrações diferentes (1\% e 5\%) a um meio de cultura contendo as bactérias. Verificaram que na presença de 1 e 5\% de xilitol ocorreu 35 e $72 \%$ de inibição do Streptococcus pneumoniae, respectivamente. Amostras de Haemophilus influenzae e Moraxella catarrhalis também foram testadas, porém não foram observadas mudanças ocasionadas pela adição do açúcar. Com esses resultados, previram que a administração de xilitol poderia interferir sobre otite média, estimulando novos estudos.

O mecanismo de ação do xilitol nas bactérias otopatogênicas não é justificado apenas pela inibição do crescimento bacteriano. A literatura descreve que o carboidrato possui propriedades que afetam a aderência dos pneumococos, impedindo sua instalação nas células da nasofaringe e dificultando a passagem até a orelha média, importante etapa da patofisiologia 
da otite média aguda (KONTIOKARI et al., ${ }^{37}$ 1998, TAPIAINEN et al., ${ }^{71}$ 2004). KONTIOKARI et al., ${ }^{37}$ 1998, confirmaram esta afirmação realizando um estudo onde foram isolados 10 amostras de Streptococcus pneumoniae, Haemophilus influenzae e Moraxella catarrhalis em um meio de cultura juntamente com células epiteliais da orofaringe coletadas de adultos saudáveis. O experimento consistiu em expor células epiteliais, bactérias e ambos em uma concentração de $5 \%$ de xilitol. Como resultado, o Streptococcus pneumoniae demonstrou uma adesividade entre 32 e 47 bactérias por célula quando não exposto ao xilitol. Quando o pneumococo foi exposto a 5\% do carboidrato, observou-se uma redução da aderência para 25 bactérias por célula. Entretanto, quando ambos tiveram contato com a concentração do açúcar, a aderência foi de 13 bactérias por célula. A aderência do Haemophilus influenziae sem a adição do xilitol variou entre 17 e 54 bactérias por célula, enquanto que contabilizou 16 bactérias por célula quando ambos (célula e microorganismo) foram submetidos a $5 \%$ do açúcar. O contato isolado com o xilitol não resultou na redução da aderência como visto no Streptococcus pneumoniae. A exposição de Moraxella catarrhalis também não demonstrou resultados significantes quanto a sua aderência.

A partir do postulado que o xilitol nas concentrações de $1 \%$ e $5 \%$ inibe o crescimento e aderência do Streptococcus pneumoniae, TAPIAINEN et al., ${ }^{68} 2001$, realizaram um estudo avaliando o efeito do xilitol na presença de frutose e sorbitol. Foi detectada marcante inibição do crescimento bacteriano na presença de $5 \%$ de xilitol, em meio básico com $0,2 \%$ de glicose. A inibição do crescimento induzida pelo xilitol foi prevenida por todas as concentrações de frutose utilizadas $(1 \%, 2,5 \%$ e $5 \%$ de frutose), enquanto a adição de $1 \%$ de 
glicose, $1 \%$ de galactose ou $1 \%$ de sacarose não alterou o efeito do xilitol e a inibição de crescimento foi detectada. O sorbitol nas concentrações de 1\%, $2,5 \%$ e $5 \%$ não teve nenhum efeito no crescimento dos pneumococos. O xilitol na concentração de $2,5 \%$ foi efetivo sozinho e quando combinado com o sorbitol. O mecanismo de ação do xilitol na inibição do crescimento dos pneumococos parece ser semelhante ao demonstrado pelo Streptococcus mutans, dando suporte à hipótese que esta inibição deve-se ao envolvimento do sistema frutose-fosfotransferase e formação do metabólito não utilizado pela célula, xilitol-5-fosfato, de maneira similar à que acontece na inibição do crescimento dos Streptococcus mutans.

Com a hipótese confirmada de que o xilitol pode interferir no metabolismo da principal bactéria otopatogênica, o Streptococcus pneumoniae, realizaram-se estudos randomizados com o objetivo de comprovar a eficácia clinica do carboidrato na prevenção de OMA. No primeiro estudo, foram recrutadas 306 crianças de creches públicas da cidade de Oulu, Finlândia, com idade média de 5 anos. As crianças foram divididas em dois grupos e monitoradas pelo período de dois meses. No grupo 1 foi administrado diariamente gomas de mascar contendo apenas sacarose (grupo controle) e no grupo 2, contendo apenas xilitol (8,4 g/dia). Os resultados obtidos demonstraram que os eventos de otite média aguda foram menores no grupo que recebeu goma de mascar contendo xilitol. Apenas 19 crianças do grupo xilitol experienciaram episódio de OMA, enquanto que no grupo que recebeu sacarose constataram 31 casos. Com esses resultados, os autores concluíram que o xilitol pareceu ter um efeito preventivo sobre a OMA (UHARI et al., ${ }^{75}$ 1996). 
O segundo estudo clínico envolveu 857 crianças saudáveis recrutadas de creches da cidade de Oulu/Finlândia. As crianças foram aleatoriamente divididas em cinco grupos: 165 receberam xarope sem xilitol (controle), 159 receberam xarope com xilitol, 178 receberam goma de mascar sem xilitol (controle), 179 fizeram uso de goma de mascar com xilitol e 176 receberam pastilha com xilitol. A dose diária de xilitol variou de $8,4 \mathrm{~g}$ (em gomas de mascar) e $10 \mathrm{~g}$ (xarope). Após três meses de acompanhamento diário observaram que 68 (41\%) crianças do grupo xarope controle tiveram pelo menos um episódio de otite média e apenas 46 (29\%) das crianças que receberam o xarope com xilitol foram afetadas. Já entre as crianças que receberam goma de mascar controle, apenas 49 (28\%) tiveram OMA, enquanto 29 (16\%) crianças que receberam a goma de mascar com xilitol foram acometidas com pelo menos um episódio de otite. Assim, a pesquisa mostrou que o xilitol é eficaz na prevenção de OMA, reduzindo significativamente suas ocorrências e diminuindo a necessidade de prescrição de antibióticos (UHARI et al., ${ }^{76}$ 1998).

TAPIAINEN et al., ${ }^{69}$ em 2002, discutiram os meios de administração do xilitol para prevenir OMA. Os autores afirmaram que a goma de mascar com xilitol reduz a incidência de OMA, porém ressaltaram que a metodologia utilizada (prescrevia consumo de gomas de mascar cinco vezes ao dia) é inaceitável para nossa realidade. Além disso, essa forma de administração é inviável para a faixa etária onde há maior incidência de otite média. Com o objetivo de encontrar uma dosagem de xilitol que possibilitasse uma menor freqüência para a sua administração, realizaram-se um estudo para mensurar o pico e duração de concentração do carboidrato detectado na saliva de crianças 
que ingeriram gomas de mascar e xarope. Para tal, 65 crianças com idade entre 1 e 6 anos foram divididas em dois grupos: G1 (receberam gomas de mascar contendo 1,68 g de xilitol) e G2 (receberam $5 \mathrm{ml}$ de xarope contendo 400 mg/l do açúcar). Amostras de saliva não estimulada foram coletadas em diferentes tempos e analisadas pelo kit enzimático D-Sorbitol/Xylitol Boehringer-Mannheim (Alemanha). Os resultados evidenciaram que as crianças que receberam gomas de mascar mantiveram concentrações salivares do carboidrato acima de $1 \%$ por tempos maiores quando comparadas às crianças que receberam xilitol em forma de xarope. No entanto, o tempo máximo onde foi detectada a concentração salivar de 1\% do açúcar não foi superior a 15 minutos. Logo após este período não foi mais possível observar essa concentração salivar necessária para se obter um efeito antimicrobiano. Com estes achados, os autores acreditam que a administração de doses mais elevadas de xilitol e em menor freqüência possa ser mais interessante para prevenir otite média aguda quando comparada com a administração de doses menores e com maior freqüência.

Pensando sobre alternativas mais viáveis para implementar a profilaxia com xilitol na prática clínica, TAPIAINEN et al., ${ }^{70}$ em 2002, realizaram o terceiro estudo clínico com o objetivo de verificar se a administração de xilitol poderia reduzir a ocorrência de OMA em crianças com quadro de infecção de vias aéreas superiores (IVAS) já instalado. Foram recrutadas 1277 crianças saudáveis matriculadas em creches de Oulu/Finlândia. Os pesquisadores acompanharam as crianças semanalmente durante 4 meses e administraram xarope com xilitol $(n=212)$, xarope controle $(n=212)$, gomas de mascar com xilitol ( $n=286)$, gomas de mascar controle $(n=280)$ ou pastilhas com xilitol 
( $n=287)$ durante os episódios confirmados de IVAS. Os autores constataram que a ocorrência de OMA no grupo controle foi semelhante ao grupo que recebeu xilitol. Assim, concluíram que a administração de xilitol durante quadros de IVAS não foi efetivo na prevenção de OMA.

TAPIAINEN et al., ${ }^{71} 2004$, realizaram um estudo com o objetivo de analisar a estrutura celular do Streptococcus pneumoniae após a exposição com xilitol. Cinco amostras de pneumococos foram expostas a concentrações de $0,5 \%$ e $5 \%$ de xilitol, $5 \%$ de glicose, $5 \%$ de frutose e $5 \%$ de sorbitol. As ultraestruturas das bactérias foram examinadas por meio de microscopia eletrônica em dois diferentes tempos após a exposição: 30 min e 2 h. Os resultados mostraram que a célula do pneumococo exposto ao xilitol por 30 min não apresentou qualquer mudança em sua morfologia, porém quando exposta por $2 \mathrm{~h}$ foi observado que a cápsula polissacarídeo tornou-se desigual e dispersa. Essas alterações não foram notadas durante a exposição dos pneumococos com os outros açúcares. Os autores sugeriram que as mudanças observadas com o acréscimo de xilitol afetaram a aderência e virulência dos pneumococos, o que explicaria a eficácia clínica do xilitol na prevenção de otite média aguda.

\subsubsection{Desvantagens do xilitol}

Apesar de ocorrer naturalmente em muitas frutas e vegetais, o xilitol apresenta efeitos colaterais associados ao seu consumo. Por ser muito lentamente absorvido pelo trato gastrintestinal pode ocorrer diarréia osmótica e 
um desconforto abdominal ocasionados pela ingestão de grande quantidade deste elemento (AKERBLOM et al. $^{1}, 1982$ ).

MAKINEN, ${ }^{42}$ 1984, KONTIOKARI et al., ${ }^{36} 1995$, e UHARI et al., ${ }^{77}$ 2001, relataram que indivíduos adultos podem tolerar até 200 g/dia sem apresentar qualquer alteração gastrointestinal, enquanto que as crianças podem tolerar até $45 \mathrm{~g} /$ dia do açúcar.

Entretanto, BASTOS e cols., ${ }^{7} 2000$, afirmaram que a dosagem diária máxima recomendada para não causar efeitos indesejáveis é de 20 g/dia, não representando assim, riscos significantes à saúde humana.

\subsection{VERNIZ}

Na odontologia o verniz é uma estratégia amplamente utilizada para a aplicação tópica de flúor com a finalidade de prevenir a cárie dentária (ELIAS, ${ }^{18}$ 2005). Geralmente, são preparados em base alcoólica que, quando aplicado na superfície seca dos dentes, têm secagem bastante rápida, apresentando ainda uma forte adesão à estrutura dentária (BASTOS et al. ${ }^{7}$, 2001).

Dessa forma, o verniz fluoretado, por exemplo, permanece por mais tempo em contato com a superficie dentária possibilitando uma liberação contínua e lenta do íon flúor. Outra vantagem da técnica é o fato de não depender da colaboração do paciente (BADER, ${ }^{5}$ 2001).

Não há no mercado um verniz que possua em sua composição o xilitol. Refletindo sobre a facilidade de aplicação de verniz em bebês, torna-se 
extremamente interessante verificar se a elaboração de tal produto seria eficaz na liberação continua do xilitol. 
3 Proposição 


\section{PROPOSIÇÃO}

O presente estudo 'in vitro' tem como objetivo:

Verificar a liberação de xilitol em saliva artificial ao longo do tempo após aplicação de verniz contendo 10 \% e 20 \% do açúcar. 


\section{Materiale Métodos}




\section{MATERIAL E MÉTODOS}

\subsection{Delineamento experimental}

Neste protocolo de estudo 'in vitro' foram testados vernizes contendo xilitol em duas concentrações diferentes: 10 e $20 \%$. Para tal, 15 blocos de dentes bovinos $(8 \times 4 \mathrm{~mm})$ foram selecionados e divididos em três grupos conforme o experimento:

Grupo 1: Em cinco blocos de esmalte bovino foi aplicado verniz de xilitol a 10\%; Grupo 2: Em cinco blocos de esmalte bovino foi aplicado verniz de xilitol a 20\%; Grupo 3: Em cinco blocos de esmalte bovino foi aplicado verniz sem xilitol (grupo controle).

Na seqüência, cada bloco foi imerso em $500 \mu \mathrm{L}$ de saliva artificial contido em tubo de microcentrífuga identificado. Foi analisada a concentração de xilitol liberada nas amostras de saliva artificial coletadas em sete diferentes tempos após a aplicação do verniz (1 h, 8 h, 12 h, 16 h, 24 h, 48 h e 72 h) utilizando-se o kit Boehringer-Mannheim/R-Biopharm (método colorimétrico). As análises foram realizadas utilizando o espectrofotômetro Ultrospec 2000/Pharmacia Biotech.

Todas as etapas do experimento foram realizadas nas dependências do Laboratório de Bioquímica da Faculdade de Odontologia de Bauru, Universidade de São Paulo. 


\subsection{Obtenção dos dentes bovinos}

Foram utilizados dentes bovinos permanentes extraídos recentemente, esterilizados com solução tamponada de formol 2\%, em pH 7,0, sob temperatura ambiente, por no mínimo 30 dias, e submetidos à análise visual, para a averiguação de possíveis manchas e trincas, situação na qual seriam excluídos da amostra.

A limpeza dos dentes selecionados foi realizada, removendo todo e qualquer resíduo de tecido gengival aderido à superfície com o auxílio de uma cureta periodontal (DUFLEX. Ind. Bras.) para preparar os dentes para o corte.

Na seqüência, as coroas foram fixadas com godiva (Kerr) em uma placa de acrílico $\left(40 \times 40 \times 5 \mathrm{~mm}^{3}\right.$. A placa foi parafusada em um aparelho de corte de precisão ISOMET Low Speed Saw (Buehler Ltd, USA) (Fig. 4.2.1) e com dois discos diamantados dupla face - XL 12205, "High concentration", 102 x 0,3 x 12,7 mm³ (Extec Corp., Enfield, CT, USA/ Ref: 12205) e um espaçador de aço inoxidável $(7 \mathrm{~cm}$ de diâmetro, $4 \mathrm{~mm}$ de espessura e orificio central de 1,3 cm) entre os discos, com velocidade de $300 \mathrm{rpm}$, refrigerado com água deionizada, foram obtidos os blocos de esmalte de $8 \times 4 \mathrm{~mm}$ da porção mais ampla da coroa, através de uma secção dupla no sentido cérvico-incisal e outra no sentido mésio-distal (Fig. 4.2.2).

Em seguida, cada bloco recebeu uma numeração para a identificação do grupo a que pertencia (Fig.4.2.3). 


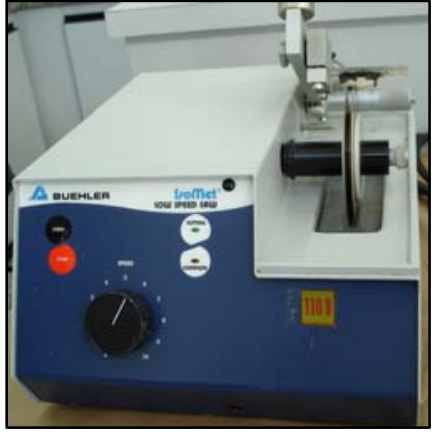

Figura 4.2.1 - Aparelho de corte ISOMET Low Speed Saw (Buehler Ltda, USA)

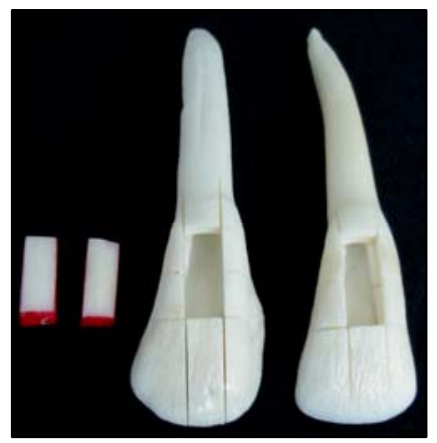

Figura 4.2.2 - Obtenção dos blocos de esmalte bovinos

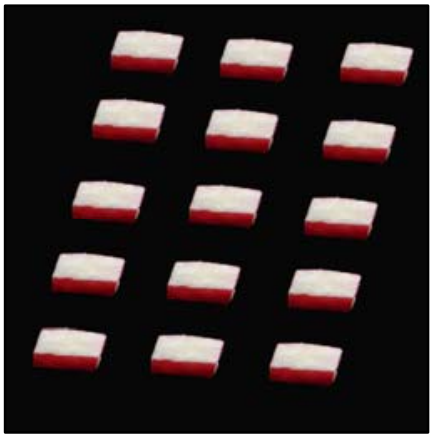

Figura 4.2.3 - Blocos $(n=15)$ de esmalte bovino $(8 \times 4 \mathrm{~mm})$ identificados

\subsection{Elaboração do verniz}

Com a colaboração da indústria FGM/Brasil foram formulados vernizes com xilitol (Xylitab ${ }^{\circledR}$ 300/DANISCO) em duas diferentes concentrações: 10 e 20\%. A escolha por essas concentrações justifica-se pelo intuito de testar um verniz contendo o máximo de xilitol sem que o mesmo perdesse suas características. Em concentração superior a $20 \%$ obteve-se um verniz repleto de glóbulos do açúcar não dissolvido o que comprometia sua utilização. Por esse motivo, optou-se por trabalhar com 10 e $20 \%$ uma vez que nessas formulações o verniz encontrava-se mais homogêneo e mais próximo das suas características usuais.

A composição básica dos vernizes incluiu colofônia (resina formadora de filme), resina sintética (formador de filme), polímero espessante (para o ajuste de viscosidade), essência, adoçante artificial, etanol (solvente) e xilitol nas concentrações já descritas. 


\subsection{Aplicação do verniz}

Os blocos selecionados para o estudo receberam uma quantidade de $4 \mathrm{mg}$ de verniz/bloco aplicado sobre o esmalte seco, com auxílio de um microbrush. Para a padronização do peso, os blocos foram pesados antes e após a aplicação do verniz para se estabelecer a quantidade exata a ser aplicada.

Os blocos foram numerados e distribuídos:

- Grupo G1 (Blocos 1, 2, 3, 4 e 5): receberam verniz de xilitol a 10\%;

- Grupo G2 (Blocos 6, 7, 8, 9 e 10): receberam verniz de xilitol a 20\%;

- Grupo G3 (Blocos 11, 12, 13, 14 e 15): receberam verniz sem xilitol (grupo controle negativo).

Após 10 min da aplicação do verniz, cada bloco foi imerso em $500 \mu \mathrm{L}$ de saliva artificial (composta por: $\mathrm{Ca}\left(\mathrm{NO}_{3}\right)_{2} \cdot \mathrm{H}_{2} \mathrm{O}$ a $1,5 \mathrm{mM} ; \mathrm{Na}_{2} \mathrm{HPO}_{4} \cdot 2 \mathrm{H}_{2} \mathrm{O}$ a 0,9 mM; $\mathrm{KCl}$ a $150 \mathrm{mM} ; \mathrm{H}_{2} \mathrm{NC}\left(\mathrm{CH}_{2} \mathrm{OH}\right)_{3}$ a $0,1 \mathrm{M}, \mathrm{NaF} 0,05 \mu \mathrm{g} / \mathrm{mL}$ e manipulada no laboratório de Bioquímica da FOB-USP) contidos em tubo de microcentrífuga e, em seguida, respeitaram-se os tempos estipulados para a troca dos blocos e coleta das salivas. 


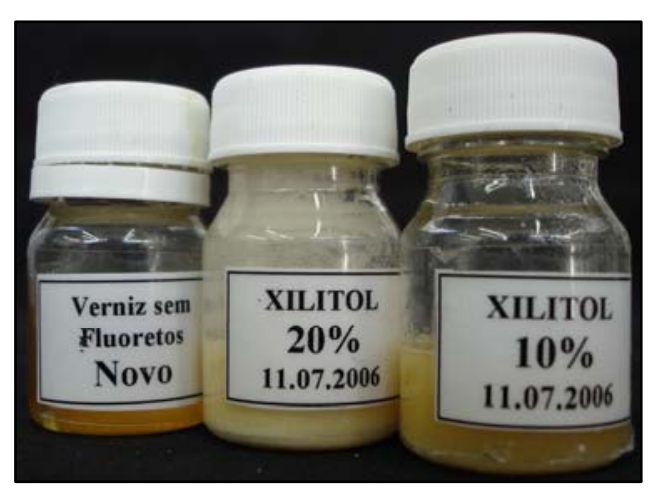

Figura 4.4.1 - Vernizes contendo xilitol (10 e 20\%) e verniz controle elaborados pela indústria FGM/Brasil

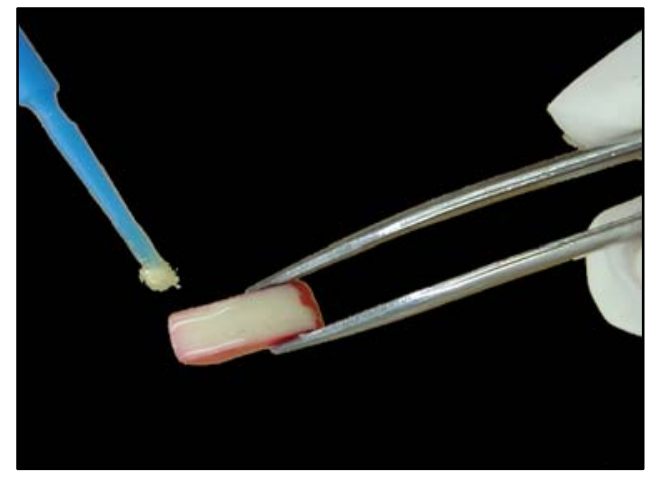

Figura 4.4.2 - Aplicação de verniz sobre o esmalte seco

\subsection{Tempos de coleta da saliva}

Previamente realizou-se um estudo piloto com o objetivo de elucidar os melhores tempos para a coleta salivar a serem pesquisados. Nesta etapa, optou-se por analisar a liberação de xilitol nos seguintes tempos: 1 h, 8 h, 16 h, $24 \mathrm{~h}$ e $48 \mathrm{~h}$. Com os resultados alcançados no estudo piloto, definiu-se acrescentar mais dois tempos de coleta: $12 \mathrm{~h}$ e $72 \mathrm{~h}$.

Assim, foram coletadas amostras de saliva artificial em 7 tempos diferentes: 1 h, 8 h, 12 h, 16 h, 24 h, 48 h e 72 h após a aplicação do verniz. Para tal, cada um dos blocos numerados de 1 a 15, após terem permanecido durante $1 \mathrm{~h}$ mergulhados em saliva artificial, foram transferidos para um outro tubo de microcentrífuga devidamente identificado e contendo a mesma quantidade de saliva. Nesta etapa, os blocos permaneceram por mais sete horas com a finalidade de simular um tempo de 8 horas após sua primeira imersão. Completado esse período, os blocos foram novamente transferidos para outros tubos onde ficaram mergulhados em saliva artificial por mais 4 
horas, simulando um tempo de 12 horas após sua primeira imersão. As trocas seguiram-se sucessivamente até completar o período de 72 horas.

Todo o experimento foi realizado à temperatura ambiente e não se utilizou agitador nas etapas em que os blocos ficaram imersos na saliva artificial. Após a coleta salivar nos tempos desejados, as amostras foram congeladas até o momento da análise.

\subsection{Análise das amostras}

Para a quantificação da liberação de xilitol em cada amostra foi realizada a análise pelo método colorimétrico, por meio do espectrofotômetro Ultrospec 2000/Pharmacia Biotech, utilizando o kit enzimático D-Sorbitol/Xylitol, Boehringer Mannheim, R-Biopharm. O presente kit contém: uma solução de 25 $\mathrm{mL}$ (fosfato de potássio/ trietanolamina; Triton X-100), três frascos de $35 \mathrm{mg}$ (diaforase, nicotinamida adenina dinucleotídeo /NAD), uma solução de cloreto de iodonitrotetrazolio/INT, três frascos contendo sorbitol desidrogenase/SDH e um frasco de solução controle D-sorbitol.

O princípio do kit enzimático é explicado pelo fato do D-Sorbitol e xilitol serem oxidados pela nicotinamida adenina dinucleotídeo (NAD) em Dfrutose ou D-Xilulose, respectivamente, na presença da enzima sorbitol desidrogenase (SDH), formando nicotinamida adenina dinucleotídeo reduzida (NADH):

$$
\begin{array}{lll}
\text { D-Sorbitol }+\mathrm{NAD}^{+} \stackrel{\mathrm{SDH}}{\longleftrightarrow} & \text { D-Frutose + NADH + } \mathrm{H}^{+} \\
\text {Xilitol }+\mathrm{NAD}^{+} \stackrel{\mathrm{SDH}}{\longleftrightarrow} & \text { D-Xilulose + NADH }+\mathrm{H}^{+}
\end{array}
$$


Nessas condições, o equilíbrio das reações parte do NAD e Dsorbitol ou xilitol, respectivamente. Entretanto, elas são favoravelmente deslocadas com a formação de NADH que, reduz na presença de cloreto de iodonitrotetrazolio (INT) a formazan, na presença de diaforase.

$$
\mathrm{NADH}+\mathrm{INT}+\mathrm{H}^{+} \stackrel{\text { Diaphorase }}{\longrightarrow} \mathrm{NAD}^{+}+\text {formazan }
$$

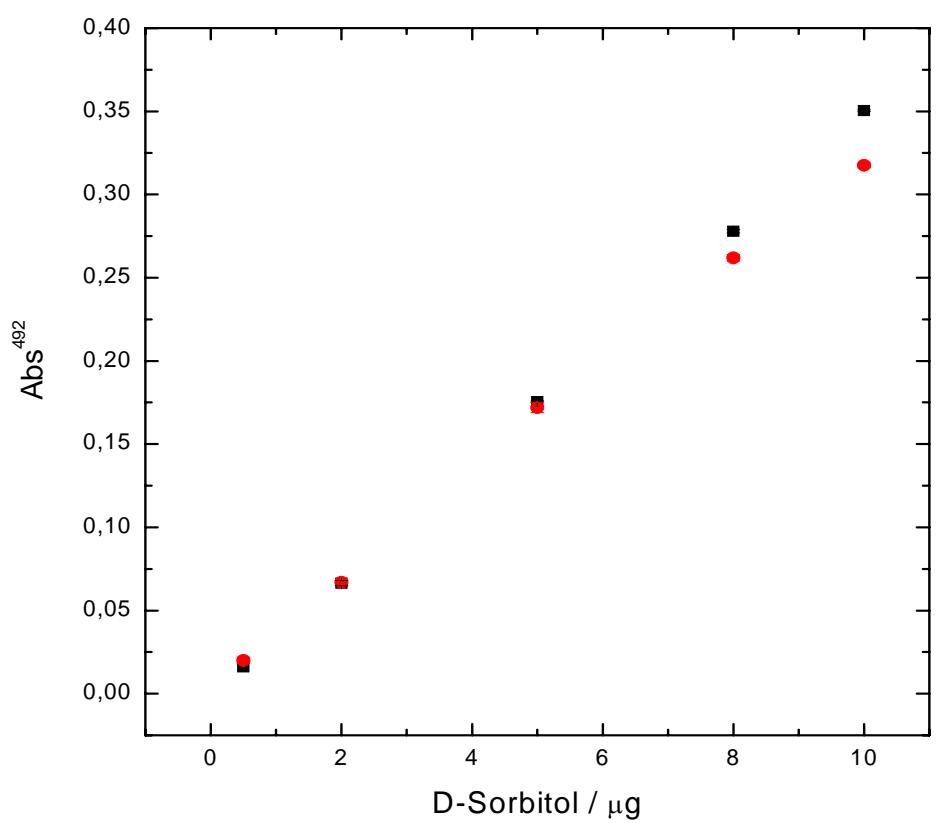

D-Sorbitol 0,1g/L (Boehringer Mannheim, R-Biopharm)

D-Sorbitol 0,1g/L SIGMA

Obteve-se, antes da análise das amostras, a curva padrão D-Sorbitol (Boehringer Mannheim, R-Biopharm) de cinco concentrações diferentes (0,5 $\mu \mathrm{g} ; 2 \mu \mathrm{g} ; 5 \mu \mathrm{g} ; 8 \mu \mathrm{g}$ e $10 \mu \mathrm{g}$ ), onde foi determinado uma linearidade dos ponto quanto lançados no gráfico (D-Sorbitol $\times \mathrm{Abs}^{492}$ ). Este resultado demonstrou boa reprodutibilidade da análise.

As análises salivares foram realizadas em duplicata, obtendo-se uma repetibilidade média das leituras de $98,6 \%$. 
Depois de obtidos os resultados em absorbância, foi utilizada a equação já determinada pelo kit enzimático para a conversão dos valores em concentração de xilitol em g/L:

$C=\frac{V \times M W}{E \times \vee \times 1000} \times A[g / L]$

onde:

$\mathrm{C}=$ concentração pesquisada

$\mathrm{V}=$ volume final $[\mathrm{mL}]$

$\mathrm{v}=$ volume da amostra $[\mathrm{mL}]$

$\mathrm{MW}=$ peso molecular do xilitol $[\mathrm{g} / \mathrm{mol}]$

$E=$ coeficiente: $19,9[\mathrm{l} \times \mathrm{mmol} \times \mathrm{cm}]$

A= Absorbância a 492 nm

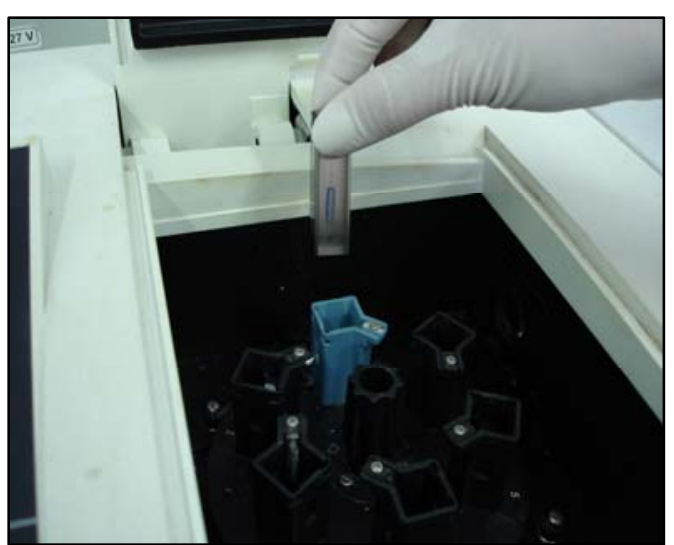

Figura 4.6.1 - Análise pelo método colorimétrico utilizando o espectrofotômetro Ultrospec 2000/Pharmacia Biotech

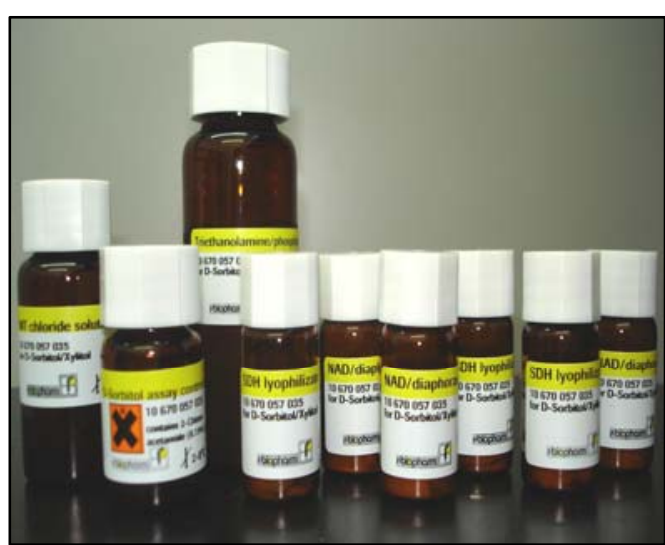

Figura 4.6.2 - Kit enzimático D-Sorbitol/Xylitol, Boehringer Mannheim, R-Biopharm 


\subsection{Análise estatística}

Estando satisfeitos os critérios de normalidade e homogeneidade dos dados, os mesmos foram submetidos à análise de variância a dois critérios (grupo e tempo) e teste de Tukey para comparações individuais. O nível de significância adotado em todos os testes foi de 5\%. 


\section{Resultados}




\section{RESULTADOS}

A análise pelo método colorimétrico permitiu a visualização nítida da diferença de liberação do açúcar nos Grupos G1 e G2. As Figuras 5.1 e 5.2 ilustram as mudanças de coloração nos diferentes intervalos de tempo.
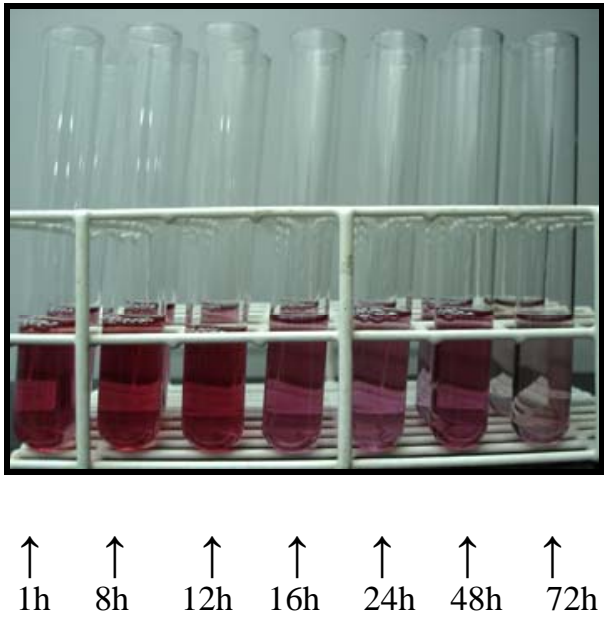

Figura 5.1 Análise pelo método colorimétrico da liberação de xilitol nos diferentes tempos de um bloco do grupo G1
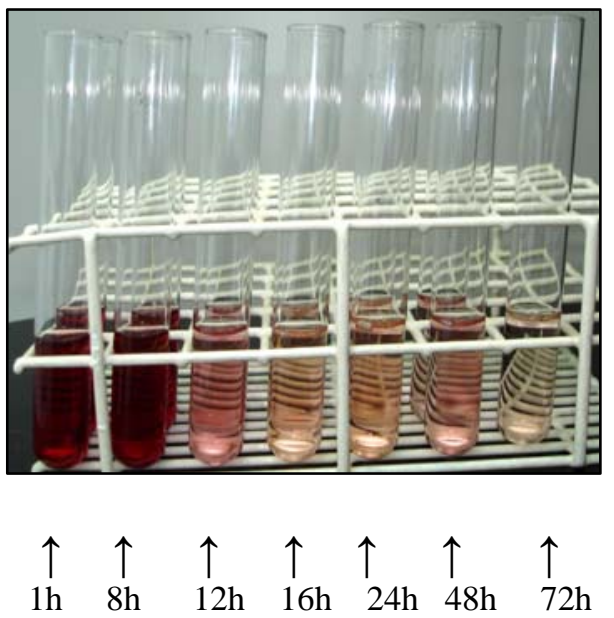

Figura 5.2 Análise pelo método colorimétrico da liberação de xilitol nos diferentes tempos de um bloco do grupo G2

A tabela 5.1 apresenta a tabulação dos valores médios de concentração de xilitol (mg/L) obtidos pelos Grupos G1 e G2 com seus respectivos valores de desvio padrão. 
Tabela 5.1 Média ( $\pm D P$ ) dos valores de concentração de xilitol em mg/L liberados pelos grupos G1 (verniz contendo xilitol a 10\%) e G2 (verniz contendo xilitol a 20\%) nos diferentes tempos.

\begin{tabular}{cll}
\hline Tempo & $\mathbf{G 1}^{\mathbf{A}}$ & $\mathbf{G 2}^{\mathbf{B}}$ \\
\hline $\mathbf{1} \mathbf{h}$ & $63,42 \pm 2,71^{\mathrm{a}}$ & $168,96 \pm 1,53^{\mathrm{a}}$ \\
$\mathbf{8} \mathbf{h}$ & $69,52 \pm 4,04^{\mathrm{a}}$ & $164,22 \pm 0,77^{\mathrm{b}}$ \\
$\mathbf{1 2} \mathbf{h}$ & $56,92 \pm 5,94^{\mathrm{b}}$ & $29,90 \pm 3,68^{\mathrm{c}}$ \\
$\mathbf{1 6} \mathbf{h}$ & $49,70 \pm 7,16^{\mathrm{c}}$ & $18,52 \pm 2,24^{\mathrm{e}}$ \\
$\mathbf{2 4} \mathbf{h}$ & $49,40 \pm 3,78^{\mathrm{c}}$ & $19,76 \pm 1,89^{\mathrm{e}}$ \\
$\mathbf{4 8} \mathbf{h}$ & $55,52 \pm 2,11^{\mathrm{bc}}$ & $24,20 \pm 0,57^{\mathrm{d}}$ \\
$\mathbf{7 2} \mathbf{h}$ & $32,66 \pm 0,87^{\mathrm{d}}$ & $12,72 \pm 0,35^{\mathrm{f}}$ \\
\hline
\end{tabular}

Valores seguidos por letras minúsculas distintas nas mesmas colunas indicam diferenças significativas entre os tempos. Letras maiúsculas indicam diferenças significativas entre os grupos $(p<0,05)$.

As análises (Anexo A) demonstraram que todos os blocos dos Grupos G1 e G2 liberaram xilitol pelo período que compreendeu o experimento (até $72 \mathrm{~h}$ ).

Comparando-se os valores de concentração de xilitol em mg/L nos grupos G1 e G2, pode-se observar que houve diferença estatisticamente significante entre os grupos (ANOVA, $F=32,68, p=0,0004$ ) e tempos (ANOVA, $F=2465,53, p=0,0000$ ). Foi observada interação entre as variáveis grupo e tempo (ANOVA, $F=1486,25, \quad p=0,0000$ ). Notou-se uma liberação significativamente maior no Grupo G2 nos tempos de $1 \mathrm{~h}(168,96 \mathrm{mg} / \mathrm{L})$ e $8 \mathrm{~h}$ (164,22 mg/L), quando comparados com o Grupo G1 (1 h=63,42 mg/L e 8 $\mathrm{h}=69,52 \mathrm{mg} / \mathrm{L})$, conforme detectado pelo teste de Tukey $(p=0,0002)$. No entanto, nos tempos de 12 h, 16 h, 24 h, 48 h e 72 h, a liberação do açúcar foi significativamente maior no Grupo G1 (56,92 mg/L; 49,70 mg/L; 49,40 mg/L; 
55,52 mg/L; 32,66 mg/L, respectivamente) em relação ao Grupo G2 (29,90 $\mathrm{mg} / \mathrm{L} ; 18,52 \mathrm{mg} / \mathrm{L} ; 19,76 \mathrm{mg} / \mathrm{L} ; 24,20 \mathrm{mg} / \mathrm{L} ; 12,72 \mathrm{mg} / \mathrm{L}$, respectivamente), conforme detectado pelo teste de Tukey $(p=0,0002)$.

Para o grupo G1, a liberação de xilitol não diferiu significativamente entre 1 e 8 h depois da aplicação do verniz. A quantidade de xilitol liberada após $12 \mathrm{~h}$ foi significativamente menor quando comparada com $1 \mathrm{~h}$ e $8 \mathrm{~h}$, mas significativamente maior quando comparada com 16 h e 24 h, que não diferiram significativamente entre si. Em $48 \mathrm{~h}$, houve um ligeiro aumento na concentração de xilitol liberado em relação a 16 h e 24 h, mas sem significância estatística. A menor liberação foi encontrada para $72 \mathrm{~h}$, que diferiu significativamente de todos os outros tempos ( $p<0,05$, teste de Tukey).

Já para o grupo G2, houve uma grande liberação nos períodos de 1 h e 8 h, que diferiram significativamente entre si. No período de 12 h houve uma redução expressiva e significativa na liberação de xilitol em comparação com os tempos de 1 h e 8 h. Nos tempos de 16 h e 24 h a liberação de xilitol não diferiu significativamente, mas foi estatisticamente inferior quando comparada aos períodos de tempos anteriores. Houve um aumento significativo na liberação de xilitol após 48 h da aplicação em relação aos períodos de 12 h, 16 h e 24 h. Os menores valores foram encontrados para 72 h, que diferiu significativamente de todos os outros períodos $(p<0,05$, teste de Tukey).

$\mathrm{Na}$ figura 5.3 podem ser observados os valores médios de concentração de xilitol em mg/L na saliva artificial onde blocos dos grupos G1 e G2 foram inseridos em diferentes tempos. 


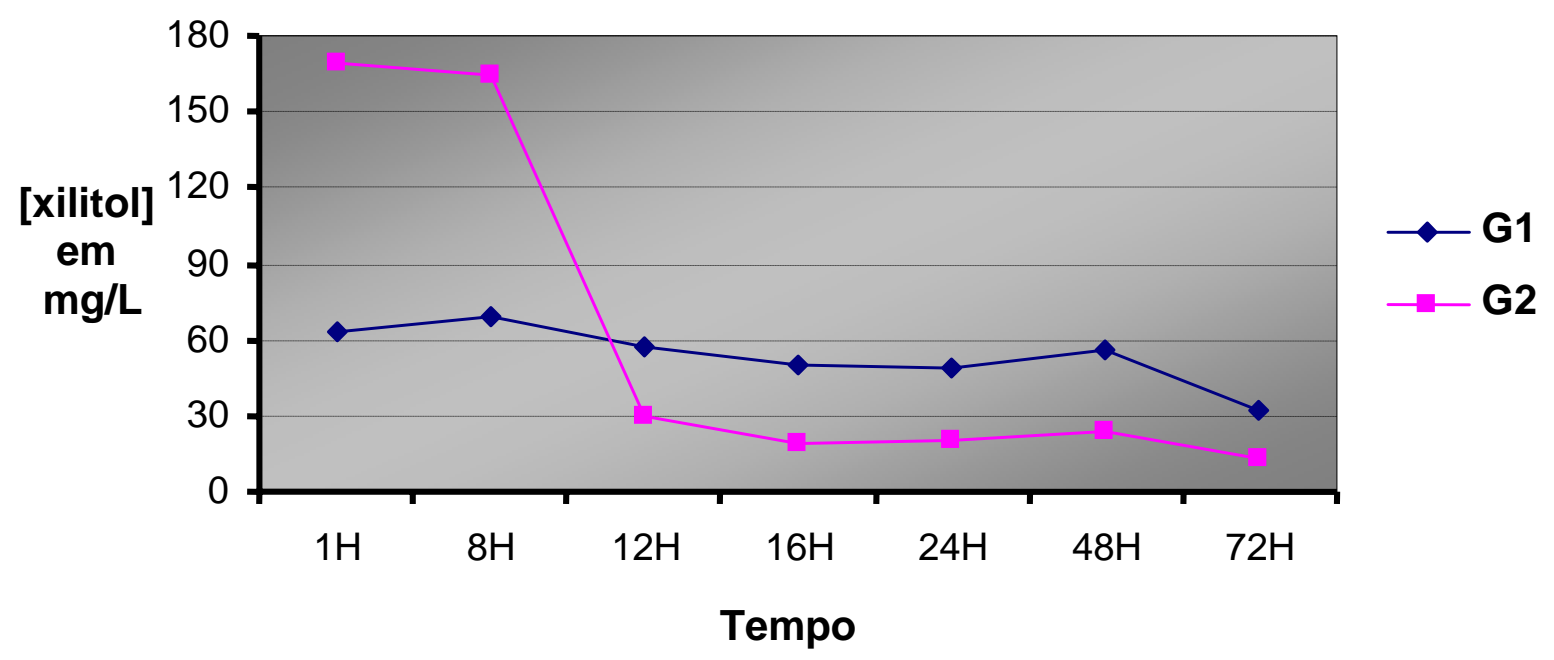

Figura 5.3 Valor médio de concentração de xilitol em $\mathrm{mg} / \mathrm{L}$ liberado pelo verniz aplicado sobre os blocos pertencentes aos grupos G1 e G2 nos diferentes tempos.

O grupo G3 (controle negativo) não apresentou qualquer liberação de xilitol dentro do intervalo de tempo analisado (72 h), conforme pode ser observado no anexo A. 
6 Discussão 


\section{DISCUSSÃO}

Os principais estudos sobre a ação do xilitol nas bactérias orais estão evidenciados na área odontológica. Descobriu-se, desde a década de 70, que a substituição total ou parcial de sacarose por xilitol na dieta demonstrou significante redução na incidência de cárie dentária em crianças e adultos jovens (SCHEININ et al. ${ }^{61}, 1975$, SCHEININ $^{62}, 1976$, GERING $^{23}, 1976$, ROGER et al. ${ }^{57}, 1991$, ISOKANGAS et al. ${ }^{29}, 1991$, MAKINEN, 1996 ${ }^{45}$, BECKERS ${ }^{8}$, 1998, ISOKANGAS et al. $\left.{ }^{31}, 2000\right)$.

Esta redução pode ser justificada pelo fato do xilitol não ser fermentado a ácidos por praticamente nenhum dos microorganismos orais, incluindo as bactérias cariogênicas como o Streptococcus mutans e Streptococcus sobrinus (BIRKHED et al. ${ }^{9}$, 1985, BECKERS ${ }^{8}, 1988$, KAKUTA et $^{2}$ al. $\left.{ }^{33}, 2003\right)$. Porém, ainda não está totalmente esclarecido o mecanismo pelo qual o xilitol age sobre as bactérias orais (BANOCZY et al. ${ }^{6}, 1985$, SCHEININ et al. ${ }^{63}, 1985$, ISOKANGAS et al. $\left.{ }^{30}, 1993\right)$.

Dentre as hipóteses propostas para explicar o efeito do açúcar na redução da incidência da cárie dentária, efeitos específicos no metabolismo e crescimento têm sido considerados. Acredita-se que o xilitol não seja utilizado como substrato pelos microorganismos orais para a produção de ácidos devido ao fato de que, ao entrar na célula bacteriana, o xilitol inicia o processo de fosforilação na via glicolítica formando um composto intermediário do metabolismo, o xilitol-5-fosfato, que não é metabolizado por nenhuma enzima. Assim, não leva à formação de ácidos e nem de energia (ATP) no final da cadeia de fosforilação, mas torna-se um produto tóxico para a célula. Com o 
intuito de livrar-se deste metabólito, a célula bacteriana exporta de seu citoplasma o composto formado. Essa captação de xilitol para o interior da célula e posterior transporte do produto para fora gera um ciclo conhecido como "Ciclo Fútil" que esgota os recursos energéticos da célula e, em última instância, provoca o desgaste e morte celular por depleção de energia (TRAHAN et al., ${ }^{73}$ 1985, ASSEV;ROLLA ${ }^{4}, 1986$, SODERLING et al., ${ }^{67} 1989$, ROGERS et al., ${ }^{57}$ 1991, TRAHAN et al., ${ }^{73} 1995$, KAKUTA et al., ${ }^{33} 2003$, MAGUIRE et al., ${ }^{41}$ 2003, GONÇALVES, ${ }^{25}$ 2004). Desta forma, o ciclo fútil resulta em inibição do crescimento e metabolismo bacteriano.

O conhecimento deste "Ciclo Fútil" possibilitou o questionamento sobre a interferência do xilitol no metabolismo de outras bactérias presentes na nasofaringe, principalmente aquelas responsáveis pelas infecções respiratórias. Assim, o primeiro estudo "in vitro" realizado com objetivo de avaliar se o xilitol também afetaria o crescimento e metabolismo de bactérias demonstrou que o Streptococcus pneumoniae sofreu inibição do seu crescimento similarmente ao já documentado para o Streptococcus mutans. Com o resultado obtido, os autores inferiram que o açúcar também poderia prevenir doenças ocasionadas por este pneumococo (KONTIOKARI et al., ${ }^{36}$ 1995).

Os estudos clínicos randomizados comprovaram que o xilitol foi eficaz na prevenção de otite média aguda (UHARI et al., ${ }^{75} 1996$; UHARI et al., ${ }^{76}$ 1998). O efeito preventivo oferecido pelo açúcar é explicado por suas propriedades antiaderentes que afetam o pneumococo e também o Haemophilus influenzae, impedindo a adesão dessas bactérias nas células nasofaríngeas e, por conseqüência, dificultando sua passagem pela tuba 
auditiva até a cavidade da orelha média (UHARI et al., ${ }^{75} 1996$, UHARI et al., ${ }^{76}$ 1998).

Apesar dos resultados promissores na prevenção de OMA, a literatura aponta alguns questionamentos referentes à viabilidade quanto à freqüência de aplicação do açúcar por meio de gomas de mascar, xaropes e/ou pastilhas que foram administradas nos estudos. A metodologia consistia no consumo de gomas, pastilhas e/ou xarope 5 vezes por dia. Os próprios autores afirmaram que esta forma de administração inviável de ser empregada clinicamente (UHARI et al., ${ }^{75}$ 1996, UHARI et al., ${ }^{76}$ 1998).

Outro ponto questionado refere-se ao desconhecimento sobre a freqüência e a dosagem mínima de xilitol que deve ser ingerida pelo sujeito para que haja o efeito preventivo. Sabe-se, no entanto, que para atingir um efeito antimicrobiano é necessária uma concentração salivar de 1\% do açúcar para inibir o crescimento e 5\% para reduzir a aderência do Streptococcus pneumoniae e Haemophilus influenzae nas células epiteliais da nasofaringe (KONTIOKARI et al., ${ }^{36}$ 1998, TAPIAINEN et al., ${ }^{69}$ 2002). As gomas de mascar e xarope com xilitol possibilitam manter a concentração salivar acima de 1\% pelo período de 15 minutos. Após esse tempo, o açúcar desaparece da saliva (TAPIAINEN et al., ${ }^{69}$ 2002).

TAPIAINEN et al., ${ }^{69} 2002$, afirmaram que a administração de doses mais elevadas de xilitol em freqüências menores poderia proporcionar um maior tempo de liberação do açúcar e conseqüentemente ser mais eficaz na prevenção de otite média aguda quando comparado com uma dose menor.

Diante desta problemática, tornou-se interessante encontrar um novo veículo de administração para o xilitol que permita manter a concentração 
salivar adequada por um tempo maior e que não necessite de várias aplicações, sendo assim, sua aplicação mais viável no sistema de saúde. Além do mais, a incidência de otite média é maior nos dois primeiros anos de vida (GOLZ et al., ${ }^{24}$ 2005, CRIPPS et al., ${ }^{13}$ 2005) e, portanto, métodos de administração alternativos devem ser encontrados para que os bebês tenham melhor acesso aos benefícios deste açúcar.

O flúor exerce seu papel no controle da desmineralização do esmalte dentário através de sua ação tópica (CATE, ${ }^{12}$ 2004, HONKALA et al., ${ }^{28} 2006$ ). Para que este íon permanecesse por mais tempo na cavidade bucal foi desenvolvido um produto que o retivesse e o liberasse de forma mais gradual e lenta, o verniz fluoretado. Este verniz é um produto freqüentemente utilizado na odontologia. Além das vantagens já citadas, este produto não requer colaboração do paciente, permitindo sua aplicação em crianças de tenra idade (BADER, ${ }^{5}$ 2001).

Partindo-se do mesmo princípio dos vernizes fluoretados, foi desenvolvido um verniz contendo xilitol. Em parceria com a indústria FGM do Brasil foi elaborado um verniz contendo o carboidrato em duas concentrações: 10 e $20 \%$. A escolha por esses valores visou a desenvolver um produto com a máxima concentração de xilitol (TAIPIANEN et al., ${ }^{69}$ 2002). Foram realizadas tentativas para a produção de vernizes com concentrações mais elevadas do açúcar. No entanto, houve uma descaracterização do produto, obtendo-se um verniz com muitos glóbulos do carboidrato, o que prejudicaria sua utilização comercial e em pesquisas.

Por ser um estudo pioneiro, não conhecendo os possíveis benefícios desta terapêutica para crianças e nem mesmo os parâmetros de 
biodisponibilidade do açúcar advindo da nova tecnologia, optou-se pela realização experimental in vitro. Foram utilizados blocos de esmalte bovino (8 x $4 \mathrm{~mm}$ ), superfície mineralizada semelhante ao esmalte humano, para a aplicação do verniz nas duas concentrações. Após a aplicação do produto, esperou-se um tempo de 10 minutos para mergulhar os blocos em saliva artificial, até que o verniz estivesse seco, simulando o mesmo procedimento realizado em consultório odontológico. O uso de saliva artificial foi previamente estabelecido devido as suas propriedades físico-químicas, favoráveis ao desenvolvimento de metodologia in vitro, já que esta possui em sua composição apenas elementos inorgânicos, melhorando a estabilidade de suas características.

Como parâmetro para a escolha dos tempos de coleta das amostras, realizou-se um estudo piloto. Previamente foram selecionados os seguintes tempos para a análise salivar: 1 h, 8 h, 12 h, 24 h e 48 h. Com os resultados, optou-se por acrescentar mais coletas nos tempos de: $16 \mathrm{~h}$ e $72 \mathrm{~h}$. O aumento do número de intervalos justifica-se pelo interesse de esclarecer melhor a diferença de concentração de xilitol liberada nestes períodos.

A análise das amostras foi realizada pelo Método Colorimétrico, utilizando o kit enzimático D-Sorbitol/Xylitol, Boehringer Mannheim, R-Biopharm (HOLGERSON et al., ${ }^{27}$ 2006, TAPIAINEN et al., ${ }^{69}$ 2002). Com os resultados das análises pode-se observar que a liberação do xilitol foi significativamente maior no Grupo G2 apenas nos dois primeiros tempos (1 h e 8 h) quando comparado com o Grupo G1. Nos tempos seguintes (12 h, 16 h, 24 h, 48 h e 72 h) notou-se o inverso, sendo a liberação de xilitol maior no Grupo G1 em relação ao Grupo G2. Além disso, pode-se constatar que a liberação do 
carboidrato no G1 permaneceu mais homogênea em todos os tempos analisados, diferentemente dos resultados do G2 onde ocorreram dois grandes picos de liberação de xilitol (1 h e 8 h) seguidos de um rápido declínio, observado a partir do tempo de $12 \mathrm{~h}$.

Foi observado que o verniz contendo $20 \%$ de xilitol apresentava-se com glóbulos visíveis do açúcar, não incorporados completamente ao produto. Este fato pode justificar a diferença encontrada entre os resultados do G1 e G2, pois o verniz contendo $10 \%$ de xilitol possuía uma notável homogeneidade em relação ao verniz aplicado no $\mathrm{G} 2$, o que pode ter favorecido um melhor controle de liberação do carboidrato.

Sabe-se que é necessária uma concentração salivar mínima de 1\% (10.000 mg/L) para que seja obtido efeito antimicrobiano sobre as bactérias otopatogênicas (KONTIOKARI et al., ${ }^{36}$ 1995, KONTIOKARI et al., ${ }^{37} 1998$, TAPIAINEN et al., ${ }^{69}$ 2002). Em relação às concentrações máximas de xilitol obtidas na análise da saliva artificial, pode-se constatar valores mais baixos que os preconizados pela literatura para prevenção de otite média. Porém, este estudo simulou a aplicação de $4 \mathrm{mg}$ de verniz em apenas uma superfície dentária. Sabe-se que um bebê de aproximadamente 2 anos e 6 meses de idade normalmente apresenta 20 dentes irrompidos na cavidade bucal, totalizando um número máximo de 40 superfícies lisas e 8 superfícies oclusais. Partindo-se deste princípio, em condições clínicas ideais, o verniz poderia ter sua concentração salivar aumentada em até 48 vezes. Considerando a maior liberação encontrada no estudo, ou seja, 168,96 mg xilitol/L, que foi obtida para o grupo G2, isto equivaleria a uma liberação total de 8.110,08 mg/L, ainda inferior ao preconizado (10.000 mg/L). Uma estratégia para se aumentar este 
valor seria aumentar a quantidade de verniz aplicado por bloco, já que neste estudo aplicaram-se apenas $4 \mathrm{mg} / \mathrm{bloco}$.

A preocupação com a dosagem provavelmente tóxica de xilitol, principalmente em crianças, deve-se aos resultados descritos pela literatura quanto às reações adversas (AKERBLOM et al. ${ }^{1}$, 1982). Estudos têm mostrado que adultos podem tolerar uma ingestão de xilitol de até 200 g/dia sem apresentar distúrbios gastrointestinais (KONTIOKARI et al., ${ }^{36}$ 1995), enquanto que as crianças toleram uma quantidade máxima de 45 g/dia do açúcar (KONTIOKARI et al., ${ }^{36}$ 1995, UHARI et al., ${ }^{76}$ 1996, UHARI et al., ${ }^{77} 2001$ ).

Apesar das diferenças de liberação encontradas nos dois vernizes, pode-se observar que a quantidade de xilitol liberada em ambos os grupos encontra-se dentro de um valor seguro quanto aos efeitos colaterais, mesmo na hipótese de realização de aplicação do produto em todas as superfícies dentárias de crianças.

Pelo padrão de liberação de xilitol encontrado no verniz contendo 10\% do açúcar, este parece ser mais efetivo que o verniz a $20 \%$. Tal afirmação pode ser justificada pelos valores de liberação de xilitol encontrados no G1 serem mais estáveis ao longo do tempo, o que poderá possibilitar uma melhor manutenção da concentração salivar necessária, o que poderia minimizar mais eficientemente as deficiências de outros veículos (gomas de mascar, xaropes e pastilhas) já empregados atualmente. Entretanto, a princípio os valores liberados parecem ser insuficientes para garantir uma concentração salivar de 1\%. Todavia, há que se considerar a possibilidade de retenção de parte do xilitol liberado pelos tecidos moles bucais, como tem sido relatado para o flúor (DUCKWORTH; MORGAN, ${ }^{17}$ 1992) o que poderia aumentar a dose 
encontrada na saliva clinicamente. Outro ponto relevante a ser considerado deve-se ao volume de saliva normalmente secretado na boca, que varia entre 1 e $2 \mathrm{~mL} / \mathrm{min}$ (DOUGLAS, ${ }^{16}$ 1994). Nestas condições, um aumento da concentração de xilitol pode ser encontrado na cavidade bucal já que a área de aplicação de verniz torna-se maior (40 superfícies lisas e 8 superfícies oclusais) e o volume de saliva somente será aumentada de 2 a 4 vezes ( 1 ou $2 \mathrm{~mL}$ ). Assim, com estas hipóteses, o padrão de liberação de xilitol pelos vernizes testados neste estudo deve ser avaliado clinicamente.

Desta forma, o verniz contendo xilitol a 10\% pareceu ser um meio de administração de xilitol que contempla uma dose segura do açúcar em sua composição, menor freqüência de aplicação e liberação lenta do carboidrato por um tempo superior aos encontrados na literatura (HOLGERSON et al., ${ }^{27}$ 2006, TAPIAINEN et al., ${ }^{69}$ 2002).

A redução do custo final do produto é outra vantagem da administração de doses menores de xilitol. Investir em estudos com o objetivo de encontrar uma dose eficaz para prevenir OMA, certamente será muito válido para o sistema público de saúde. Na Finlândia é estimado um custo anual de aproximadamente 138 milhões de dólares para o tratamento de otite média, enquanto são gastos US\$ 3 bilhões nos Estados Unidos (GATES, ${ }^{21} 1996$, KAPLAN et al., ${ }^{34}$ 1997, NIEMELA et al., ${ }^{52}$ 1999, ALSARRAF; GATES, ${ }^{3}$ 1999). Estudos desta natureza ainda não foram realizados no Brasil. 
7 Conclusões 


\section{CONCLUSÕES}

Comparando os resultados obtidos pelos grupos G1, G2 e G3 pode-se concluir que:

Durante todo o período de análise $(72$ h) foi observada liberação de xilitol pelos vernizes utilizados nos grupos G1 e G2;

Durante todo o período de análise (72 h) não foi observada liberação de xilitol pelo verniz utilizado no grupo G3;

* Os grupos G1 e G2 apresentaram diferenças estatisticamente significantes em relação à liberação de xilitol nos diferentes intervalos de tempo;

* O verniz contendo $20 \%$ de xilitol teve maior liberação do açúcar nos dois primeiros períodos de tempo (1 h e 8 h) seguido de rápido declínio nos demais períodos (12 h, 16 h, 24 h, 48 h e 72 h);

* O verniz contendo $10 \%$ de xilitol apresentou menores níveis de liberação do açúcar em relação ao verniz a 20\% nos primeiros intervalos de tempo (1 h e 8 h). Nos demais períodos (12 h, 16 h, 24 h, 48 h e 72 h), observou-se liberação mais elevada; 
Quando foram considerados todos os intervalos de tempo analisados, o verniz contendo $10 \%$ de xilitol apresentou maior homogeneidade nos valores de concentração do açúcar liberado em saliva artificial;

* Estudos clínicos testando a liberação de xilitol quando aplicado por verniz a $10 \%$ e $20 \%$ do açúcar são necessários para um melhor conhecimento da real concentração de xilitol que será disponibilizada na saliva humana. 
Anexo A 
ANEXO A - Tabelas com os valores de absorbância obtidos pela análise em duplicata (análise 1 e 2), valor médio de absorbância e concentração de xilitol ( $\mathrm{mg} / \mathrm{L}$ ) obtidos por cada bloco em cada um dos grupos (G1, G2 e G3):

Tabela 1 Valores de absorbância e concentração de xilitol no bloco 1 (G1)

\begin{tabular}{ccccc}
\hline Tempo & $\begin{array}{c}\text { Análise } \\
\mathbf{1}\end{array}$ & $\begin{array}{c}\text { Análise } \\
\mathbf{2}\end{array}$ & $\begin{array}{c}\text { Valor Médio } \\
\text { Absorbância }\end{array}$ & $\begin{array}{c}\text { Valor [xilitol] em } \\
\text { mg/L }\end{array}$ \\
\hline $\mathbf{1 h}$ & 0,561 & 0,565 & 0,563 & 65,7 \\
$\mathbf{8 h}$ & 0,649 & 0,652 & 0,6505 & 75,9 \\
$\mathbf{1 2 h}$ & 0,55 & 0,554 & 0,552 & 64,3 \\
$\mathbf{1 6 h}$ & 0,492 & 0,496 & 0,494 & 57,6 \\
$\mathbf{2 4 h}$ & 0,429 & 0,425 & 0,427 & 49,7 \\
$\mathbf{4 8 h}$ & 0,503 & 0,504 & 0,5035 & 58,7 \\
$\mathbf{7 2 h}$ & 0,286 & 0,288 & 0,287 & 33,4 \\
\hline
\end{tabular}

Tabela 2 Valores de absorbância e concentração de xilitol no bloco 2 (G1)

\begin{tabular}{ccccc} 
Tempo & $\begin{array}{c}\text { Análise } \\
\mathbf{1}\end{array}$ & $\begin{array}{c}\text { Análise } \\
\mathbf{2}\end{array}$ & $\begin{array}{c}\text { Valor Médio } \\
\text { Absorbância }\end{array}$ & $\begin{array}{c}\text { Valor [xilitol] em } \\
\text { mg/L }\end{array}$ \\
\hline $\mathbf{1 h}$ & 0,512 & 0,518 & 0,515 & 60,0 \\
$\mathbf{8 h}$ & 0,566 & 0,564 & 0,565 & 65,8 \\
$\mathbf{1 2 h}$ & 0,437 & 0,441 & 0,439 & 51,1 \\
$\mathbf{1 6 h}$ & 0,356 & 0,362 & 0,359 & 41,8 \\
$\mathbf{2 4 h}$ & 0,366 & 0,37 & 0,368 & 42,9 \\
$\mathbf{4 8 h}$ & 0,434 & 0,429 & 0,4315 & 50,3 \\
$\mathbf{7 2 h}$ & 0,274 & 0,279 & 0,2765 & 32,2 \\
\hline
\end{tabular}

Tabela 3 Valores de absorbância e concentração de xilitol no bloco 3 (G1)

\begin{tabular}{ccccc}
\hline Tempo & $\begin{array}{c}\text { Análise } \\
\mathbf{1}\end{array}$ & $\begin{array}{c}\text { Análise } \\
\mathbf{2}\end{array}$ & $\begin{array}{c}\text { Valor Médio } \\
\text { Absorbância }\end{array}$ & $\begin{array}{c}\text { Valor [xilitol] } \\
\text { mg/L }\end{array}$ \\
\hline $\mathbf{1 h}$ & 0,528 & 0,52 & 0,524 & 61,0 \\
$\mathbf{8 h}$ & 0,611 & 0,62 & 0,6155 & 71,0 \\
$\mathbf{1 2 h}$ & 0,532 & 0,537 & 0,5345 & 62,3 \\
$\mathbf{1 6 h}$ & 0,487 & 0,491 & 0,489 & 57,0 \\
$\mathbf{2 4 h}$ & 0,434 & 0,429 & 0,4315 & 50,3 \\
$\mathbf{4 8 h}$ & 0,478 & 0,484 & 0,481 & 56,0 \\
$\mathbf{7 2 h}$ & 0,288 & 0,293 & 0,2905 & 33,8 \\
\hline
\end{tabular}

Tabela 4 Valores de absorbância e concentração de xilitol no bloco 4 (G1)

\begin{tabular}{ccccc}
\hline Tempo & $\begin{array}{c}\text { Análise } \\
\mathbf{1}\end{array}$ & $\begin{array}{c}\text { Análise } \\
\mathbf{2}\end{array}$ & $\begin{array}{c}\text { Valor Médio } \\
\text { Absorbância }\end{array}$ & $\begin{array}{c}\text { Valor } \\
{[\text { [xilitol] }} \\
\text { mg/L }\end{array}$ \\
\hline $\mathbf{1 h}$ & 0,562 & 0,564 & 0,563 & 65,6 \\
$\mathbf{8 h}$ & 0,576 & 0,581 & 0,5785 & 67,4 \\
$\mathbf{1 2 h}$ & 0,457 & 0,455 & 0,456 & 53,1 \\
$\mathbf{1 6 h}$ & 0,392 & 0,389 & 0,3905 & 45,5 \\
$\mathbf{2 4 h}$ & 0,446 & 0,452 & 0,449 & 52,3 \\
$\mathbf{4 8 h}$ & 0,478 & 0,488 & 0,483 & 56,3 \\
$\mathbf{7 2 h}$ & 0,273 & 0,275 & 0,274 & 31,9 \\
\hline
\end{tabular}


Tabela 5 Valores de absorbância e concentração de xilitol no bloco 5 (G1)

\begin{tabular}{ccccc}
\hline Tempo & $\begin{array}{c}\text { Análise } \\
\mathbf{1}\end{array}$ & $\begin{array}{c}\text { Análise } \\
\mathbf{2}\end{array}$ & $\begin{array}{c}\text { Valor Médio } \\
\text { Absorbância }\end{array}$ & $\begin{array}{c}\text { Valor } \\
{[\text { [xilitol] }} \\
\text { mg/L }\end{array}$ \\
\hline $\mathbf{1 h}$ & 0,555 & 0,557 & 0,556 & 64,8 \\
$\mathbf{8 h}$ & 0,579 & 0,58 & 0,5795 & 67,5 \\
$\mathbf{1 2 h}$ & 0,463 & 0,461 & 0,462 & 53,8 \\
$\mathbf{1 6 h}$ & 0,399 & 0,401 & 0,4 & 46,6 \\
$\mathbf{2 4 h}$ & 0,443 & 0,446 & 0,4445 & 51,8 \\
$\mathbf{4 8 h}$ & 0,481 & 0,486 & 0,4835 & 56,3 \\
$\mathbf{7 2 h}$ & 0,276 & 0,274 & 0,275 & 32,0 \\
\hline
\end{tabular}

Tabela 6 Valores de absorbância e concentração de xilitol no bloco 6 (G2)

\begin{tabular}{ccccc}
\hline Tempo & $\begin{array}{c}\text { Análise } \\
\mathbf{1}\end{array}$ & $\begin{array}{c}\text { Análise } \\
\mathbf{2}\end{array}$ & $\begin{array}{c}\text { Valor Médio } \\
\text { Absorbância }\end{array}$ & $\begin{array}{c}\text { Valor } \\
{[\text { xilitol] }} \\
\text { mg/L }\end{array}$ \\
\hline $\mathbf{1 h}$ & 1,453 & 1,456 & 1,4545 & 169,5 \\
$\mathbf{8 h}$ & 1,411 & 1,412 & 1,4115 & 164,5 \\
$\mathbf{1 2 h}$ & 0,273 & 0,274 & 0,2735 & 31,8 \\
$\mathbf{1 6 h}$ & 0,156 & 0,156 & 0,156 & 18,1 \\
$\mathbf{2 4 h}$ & 0,162 & 0,159 & 0,1605 & 18,7 \\
$\mathbf{4 8 h}$ & 0,21 & 0,213 & 0,2115 & 24,6 \\
$\mathbf{7 2 h}$ & 0,111 & 0,113 & 0,112 & 13,0 \\
\hline
\end{tabular}

Tabela 7 Valores de absorbância e concentração de xilitol no bloco 7 (G2)

\begin{tabular}{ccccc} 
Tempo & $\begin{array}{c}\text { Análise } \\
\mathbf{1}\end{array}$ & $\begin{array}{c}\text { Análise } \\
\mathbf{2}\end{array}$ & $\begin{array}{c}\text { Valor Médio } \\
\text { Absorbância }\end{array}$ & $\begin{array}{c}\text { Valor [xilitol] } \\
\text { mg/L }\end{array}$ \\
\hline $\mathbf{1 h}$ & 1,411 & 1,443 & 1,427 & 166,3 \\
$\mathbf{8 h}$ & 1,401 & 1,399 & 1,4 & 163,2 \\
$\mathbf{1 2 h}$ & 0,278 & 0,276 & 0,277 & 32,2 \\
$\mathbf{1 6 h}$ & 0,145 & 0,143 & 0,144 & 16,7 \\
$\mathbf{2 4 h}$ & 0,161 & 0,159 & 0,16 & 18,6 \\
$\mathbf{4 8 h}$ & 0,21 & 0,208 & 0,209 & 24,3 \\
$\mathbf{7 2 h}$ & 0,108 & 0,106 & 0,107 & 12,4 \\
\hline
\end{tabular}

Tabela 8 Valores de absorbância e concentração de xilitol no bloco 8 (G2)

\begin{tabular}{ccccc}
\hline Tempo & $\begin{array}{c}\text { Análise } \\
\mathbf{1}\end{array}$ & $\begin{array}{c}\text { Análise } \\
\mathbf{2}\end{array}$ & $\begin{array}{c}\text { Valor Médio } \\
\text { Absorbância }\end{array}$ & $\begin{array}{c}\text { Valor [xilitol] } \\
\text { mg/L }\end{array}$ \\
\hline $\mathbf{1 h}$ & 1,457 & 1,461 & 1,459 & 170,1 \\
$\mathbf{8 h}$ & 1,415 & 1,402 & 1,4085 & 164,2 \\
$\mathbf{1 2 h}$ & 0,208 & 0,205 & 0,2065 & 24,0 \\
$\mathbf{1 6 h}$ & 0,159 & 0,153 & 0,156 & 18,1 \\
$\mathbf{2 4 h}$ & 0,196 & 0,189 & 0,1925 & 22,4 \\
$\mathbf{4 8 h}$ & 0,201 & 0,198 & 0,1995 & 23,2 \\
$\mathbf{7 2 h}$ & 0,107 & 0,105 & 0,106 & 12,3 \\
\hline
\end{tabular}


Tabela 9 Valores de absorbância e concentração de xilitol no bloco 9 (G2)

\begin{tabular}{ccccc}
\hline Tempo & $\begin{array}{c}\text { Análise } \\
\mathbf{1}\end{array}$ & $\begin{array}{c}\text { Análise } \\
\mathbf{2}\end{array}$ & $\begin{array}{c}\text { Valor Médio } \\
\text { Absorbância }\end{array}$ & $\begin{array}{c}\text { Valor [xilitol] } \\
\text { mg/L }\end{array}$ \\
\hline $\mathbf{1 h}$ & 1,457 & 1,456 & 1,4565 & 169,8 \\
$\mathbf{8 h}$ & 1,406 & 1,406 & 1,406 & 163,9 \\
$\mathbf{1 2 h}$ & 0,248 & 0,244 & 0,246 & 28,6 \\
$\mathbf{1 6 h}$ & 0,147 & 0,151 & 0,149 & 17,3 \\
$\mathbf{2 4 h}$ & 0,156 & 0,154 & 0,155 & 18,0 \\
$\mathbf{4 8 h}$ & 0,212 & 0,208 & 0,21 & 24,4 \\
$\mathbf{7 2 h}$ & 0,111 & 0,109 & 0,11 & 12,8 \\
\hline
\end{tabular}

Tabela 10 Valores de absorbância e concentração de xilitol no bloco 10 (G2)

\begin{tabular}{ccccc}
\hline Tempo & $\begin{array}{c}\text { Análise } \\
\mathbf{1}\end{array}$ & $\begin{array}{c}\text { Análise } \\
\mathbf{2}\end{array}$ & $\begin{array}{c}\text { Valor Médio } \\
\text { Absorbância }\end{array}$ & $\begin{array}{c}\text { Valor [xilitol] } \\
\text { mg/L }\end{array}$ \\
\hline $\mathbf{1 h}$ & 1,45 & 1,451 & 1,4505 & 169,1 \\
$\mathbf{8 h}$ & 1,417 & 1,42 & 1,4185 & 165,3 \\
$\mathbf{1 2 h}$ & 0,284 & 0,281 & 0,2825 & 32,9 \\
$\mathbf{1 6 h}$ & 0,189 & 0,196 & 0,1925 & 22,4 \\
$\mathbf{2 4 h}$ & 0,179 & 0,184 & 0,1815 & 21,1 \\
$\mathbf{4 8 h}$ & 0,222 & 0,199 & 0,2105 & 24,5 \\
$\mathbf{7 2 h}$ & 0,111 & 0,115 & 0,113 & 13,1 \\
\hline
\end{tabular}

Tabela 11 Valores de absorbância e concentração de xilitol (mg/L) obtidos no Grupo G3 (grupo controle)

\begin{tabular}{cccccc}
\hline Bloco & Tempo & $\begin{array}{c}\text { Análise } \\
\mathbf{1}\end{array}$ & $\begin{array}{c}\text { Análise } \\
\mathbf{2}\end{array}$ & $\begin{array}{c}\text { Valor Médio } \\
\text { Absorbância }\end{array}$ & $\begin{array}{c}\text { Valor } \\
{\left[\begin{array}{c}\text { [xilitol] } \\
\mathbf{m g} / \mathrm{L}\end{array}\right.}\end{array}$ \\
$\mathbf{1 1}$ & $72 \mathrm{~h}$ & 0 & 0 & 0 & 0 \\
12 & $72 \mathrm{~h}$ & 0 & 0 & 0 & 0 \\
13 & $72 \mathrm{~h}$ & 0 & 0 & 0 & 0 \\
14 & $72 \mathrm{~h}$ & 0 & 0 & 0 & 0 \\
15 & $72 \mathrm{~h}$ & 0 & 0 & 0 & 0 \\
\hline
\end{tabular}




\section{Referências Bibliográficas}




\section{REFERÊNCIAS BIBLIOGRÁFICAS}

1. Akerblon HK, Koivukangas KT, Puukka R, Mononen M. The tolerance of increasing amounts of dietary xylitol in children. Int J Vitam Nutr Res. $1982 ; 22: 53-66$.

2. Almeida CIR, Almeida RR. Otite média aguda. In: Sociedade Brasileira de Otorrinolaringologia. Tratado de Otorrinolaringologia. Roca; 2003.p.21-27.

3. Alsarraf R, Gates GA. The real cost of otitis media. Acta Paediatr. 1999; 88: 487-88.

4. Assev S, Rolla G. Further studies on the growth inhibition of some oral bacteria by xylitol. Acta Pathol Microbiol Immunol Scand. 1983; 91:261265.

5. Bader JD, Shugars DA, Bonito AJ. A systematic review of selected caries prevention and management methods. Comm Dent Oral Epidemiol.2001;29(6):399-411.

6. Banoczy J, Orsos M, Pienihakkinen K, Scheinin A. Collaborative WHO xylitol field studies in Hungary - Saliva levels of Streptococcus mutans. Acta Odontol Scand. 1985; 43: 367-70.

7. Bastos JRM, Heintze SD, Prado SV. Contribuição ao estudo da toxicologia do xilitol e do flúor. UFES Rev Odontol. 2000; 2(2):78-84.

8. Beckers HJA. Influence of xylitol on growth, establishment, and cariogenicity of Streptococcus mutans in dental plaque of rats. Caries Res. 1988; 22 (3):167-73. 
9. Birkhed D, Kalfas S, Svensater G, Edwardsson S. Microbiological aspects of some caloric sugar substitutes. Int. Dent. J. 1985;35: 9-17.

10. Blomgren K, Pitkaranta A. Current challenges in diagnosis of acute otitis media. Int J Pediatric Otorhinolaryngol. 2005;69: 295-299.

11. Borg E. et al. Language development in hearing impaired children. Int J Pediatric Otorhinolaryngol.2002;65:15-26.

12. Cate JMT. Fluorides in caries prevention and control: empiricism or science. Caries Research. 2004; 38:254-257.

13. Cripps A, Otczyk D, Kyde JM. Bacterial otitis media: a vaccine preventable disease? Vaccine.2005; 23: 2304-2310.

14. Cunha, LSC. Uso do xilitol como agente anticariogênico. [Monografia]. Bauru (SP):Faculdade de Odontologia de Bauru, Universidade de São Paulo; 2003.

15. Dagan R, Leibovitz E, Cheletz G. Antibiotic treatment in acute otitis media promotes superinfection with resistant Streptococcus pneumoniae carried before initiation of treatment. J Infect Dis. 2001; 183:880-886.

16. Douglas CR. Tratado de fisiologia aplicada às ciências da saúde. São Paulo: Robe Editora, 1994.

17.Duckworth RM, Morgan SN, Gilbert RJ. Oral fluoride measurements for estimation of the anti-caries efficacy of fluoride treatments. $\mathrm{J}$ Dent Res.1992; 71:836-40.

18. Elias F. Influência do complexo flúor-xilitol no controle da placa dentária e sangramento gengival em pacientes herbiátricos com aparelho 
ortodôntico fixo. [Dissertação]. Bauru (SP): Faculdade de Odontologia de Bauru, Universidade de São Paulo;2005.

19. Eskola J, Kilpi T. Potential of bacterial vaccines in the prevention of acute otitis media. Pediatric Infect Dis J. 2000;19:72-78.

20. Fried VM, Mukuc DM, Rooks RN. Ambulatory health care visits by children: principal diagnosis and place of visit. Vital Health Stat.1998;13: $1-23$.

21. Gates GA. Cost-effectiveness considerations in otitis media treatment. Otolaryngol Head Neck Surg. 1996; 114:525-30.

22. Gates GA, Klein JO, Lim DJ. Recent advances in otitis media: definitions, terminology and classification of otitis media. Ann Otol Rhinol Laryngol .2002; 111: 8-18.

23. Gehring F, Makinen KK, Larmas M, Sheinen A. Turku studies X Ocurrence of polysaccharide forming streptococci and ability of the mixed plaque microbiota to ferment various carbohydrates. Acta Odontol Scand.1976; 36 (6):329-43.

24. Golz A, Netzer A, Westerman T, Westerman LM, Gilbert G, Joachims H, Goldenberg D. Reading performance in children with otitis media. Otolaryngology-Head and Neck Surgery. 2005 Mar; 132 (3): 495-499.

25. Gonçalves NCLAV. Efeito da associação de polióis e outros agentes anticariogênicos sobre estreptococos do grupo mutans e inibição da desmineralização do esmalte dental [tese] Piracicaba (SP): UNICAMP; 2004. 
26. Gonzáles CDLT. Etiology of otitis media. In: Sih T, Chinski A, Eavey R. II Manual of Pediatric Otorhinolaryngology. IAPO/IFOS. 2001:222-228.

27. Holgerson PL, Blicks CS, Sjostrom I, Oberg M, Twetman S. Xylitol concentration in saliva and dental plaque after use of various xylitolcontaining products. Caries Res.2006;40(5):393-397.

28. Honkala E, Honkala S, Shyama M, Al-Mutaya SA. Field trial on caries prevention with xylitol candies among disabled school students. Caries Res.2006;40(6):508-13.

29. Isokangas P, Tenovuo J, Soderling E, Mannisto H, Makinen KK. Dental caries and mutans streptococci in the proximal areas of molars affected by the habitual use of xylitol chewing gum. Caries Res. 1991; 25 (6): 444-8.

30. Isokangas P, Makinen KK, Tiekso J, Alanen P. Long-term effect of xilitol chewing gum in the prevention of dental caries: a follow-up 5 years after termination of a prevention program. Caries Res. 1993; 27: 495-98.

31. Isokangas $P$, Soderling E, Pienihakkinen K, Alanen P. Ocurence of dental decay in children after maternal consumption of xylitol chewing gun a follow-up from 0 to 5 years of age. Caries Res. 2000; 34: 225-28.

32. Joki-Erkkila VP, Laipalla $P$, Pukander J. Increase in paediatric acute otitis media diagnosed by primary care in two Finnish municipalities: 1994-5 versus 1978-9. Epidemiol Infect. 1998; 121:529-34.

33. Kakuta H, Iwami $\mathrm{Y}$, Mayanagi H, Takahashi N. Xylitol inhibition of acid production and growth of mutans Streptococci in the presence of various 
dietary sugars under strictly anaerobic conditions. Caries Res. 2003; 37 (6): 404-9.

34. Kapplan B; Wandstat TL, Cunningham JR. Overall cost in the treatment of otitis media. Pediatric Infect Dis J. 1997; 16:9-11.

35. Katz J. Tratado de Audiologia Clínica. Ed. Manole: 4ª Ed: 1999.

36. Kontiokari T. Effect of xylitol on growth of nasopharyngeal bacteria invitro. Antimicrobial agents and chemotherapy. 1995; 39 (8): 1820-23.

37. Kontiokari T, Uhari, M, Koskela M. Antiadhesive effects os xylitol on otopathogenic bacteria. Journal of Antimicrobial Chemotherapy. 1998; 41: 563-65.

38. Lanphear BP, Byrd RS, Auinger P, Hall CB. Increasing prevalence of recurrent otitis media among children in the United States. Pediatrics. 1997; 99: E1.

39. Lubianca Neto JF, Hemb L, Silva DB. Systematic literature review of modifiable risk factors for recurrent acute otitis media in childhood. $\mathrm{J}$ Pediat. 2006;82:87-96.

40. Lynch H, Milgron P. Xylitol and dental caries: An overview for clinicians. J Calif Dent Assoc. 2003; 31 (3):205-9.

41. Maguire A, Rugg-Gunn AJ. Xylitol and caries prevention - is it a magic bullet? Br Dent J 2003; 194 (8): 429-36.

42. Makinen KK. Effect of long-term, peroral administration of sugar alcohols on man. Swed Dent J. 1984; 8:113-124. 
43. Makinen KK. Latest dental studies on xylitol and mechanisms of action of xylitol in caries limitation. In: Grenby TH. Progress in Sweeteners, Elsevier, NY, 331-362, 1989.

44. Makinen KK. Prevention of dental caries with xylitol - A potential dietary procedure for self care and population level use in young adults. J Am College Health.1993; 41:172-180.

45. Makinen KK, Chen CY, Makinen PL, Bennett CA, Isokangas PJ, Paper Jr HR. Properties of role saliva and dental plaque inrelation to 40-month consumption of chewing gums containing xylitol, sorbitol or sucrose. Caries Res. 1996; 30(3):180-88.

46. Makinen KK, Makinen PL, Pape HR, Peldyak J. Conclusion and review of the "Michigan Xylitol Programme" (1986-1995) for the prevention of dental caries. Int Dent J.1996, (1):46: 22-34.

47. Makinen KK. The rocky road of xylitol to its clinical application. J Dent Res. 2000; 79(6): 1352-55.

48. Makinen KK. Can the pentitol-hexitol theory explain the clinical observations made with xylitol? Medical Hypotheses. 2000; 54 (4): 603613.

49. Marone SAM, Lorenzi MC. Disfunção Tubária. In: Sociedade Brasileira de Otorrinolaringologia. Tratado de Otorrinolaringologia. Roca; 2003. p.54-63.

50. Miller AJ, Gianoli GJ. Eustachian tube dysfunction. J La State Med Soc.1996; 148:329-333. 
51. Mouton C, Scheinin A, Makinen KK. Effect of xylitol chewing gum on plaque quantity and quality. Acta Odontol Scand. 1975; 33(5):251-7.

52. Niemela $M$, Uhari $M$, Mottonen $M$, Pokka T. Costs arising from otitis media. Acta Paediatr. 1999; 88: 553-6.

53. Northern JL, Downs MP. Otite media. In: Northern JL, Downs MP Audição na Infância. Guanabara Koogan; 2002.p.55-73.

54. Paradise JL, Rockette HE, Colborn K. Otitis media in 2253 Pittsburgharea infants: prevalence and risk factors during the first two years of life. Pediatrics.1997; 99:318-33.

55. Paradise J. Abordagem da Otite média. In: Sih T. Manual de Otorrinolaringologia Pediátrica da IAPO. São Paulo: Brasil;1997.p.26169.

56. Pelton S. Prevention of acute and recurrent otitis media. The Lancet. 2000; 356 (21): 1370-1371.

57. Rogers AH; Pilowisky KA, Zilm PS, Gully NJ. Effects of pulsing with xylitol on mixed continuous cultures of oral streptococci. Aust Dent $\mathrm{J}$. $1991 ; 36(3): 231-5$

58. Rovers MM, Schilder AGM, Zielhuis GA, Rosenfeld RM. Otitis Media. The Lancet. 2004;363 (7): 465-473.

59. Santos TMT. Otite Média: Implicações para o desenvolvimento da linguagem. In: Schochat E. Processamento Auditivo. Lovise; 1996.p.106124. 
60. Scheinin A, Makinen KK, Ylitalo K. Turku sugar studies V. final report on the effect of sucrose, fructose and xylitol diets on the caries incidence in man. Acta Odontol Scand. 1975; 33 (70): 67-104.

61. Sheinin A. Turku sugar studies XVIII incidence of dental caries in relation to 1-year consumption of xylitol chewing gum. Acta Odontol Scand. 1975; 33 (5):269-78.

62. Scheinin A. Caries control through the use of sugar substitutes. Int Dent J. $1976 ; 26: 4-13$.

63. Scheinin A, Banoczy J. Xylitol and caries: the collaborative WHO oral disease preventive program in Hungary. Int.Dent. J.1985; 35:50-57.

64. Sih TM. Otite média recorrente. In: Sociedade Brasileira de Otorrinolaringologia. Tratado de Otorrinolaringologia. Roca; 2003.p.2837.

65. Sintes JL, Boneta AE, Stewart B, Volpe AR. Anticaries efficacy of a sodium monofluorphosphate dentifrice containing xylitol in a dicalcium phosphate dihydrate base. A 30 month caries clinical study in Costa Rica. Am J Dent. 2002; 15(4): 215-9.

66. Sociedade Brasileira de Otorrinolaringologia. Consenso sobre Otites Médias - Revisão, 2001. p. 3-13.

67. Soderling E, Pihlanto-Leppala A. Uptake and expulsion of C-xylitol by xylitol-cultured Streptococcus mutans ATCC 25175 in vivo. Scand J Dent Res. 1989; 97:511-9. 
68. Tapiainen T, Kontiokari T, Sammalkivi L, Ikaheimo I, Koskela M, Uhari M. Effect of xylitol on growth of Streptococcus pneumoniae in the presence of fructose and sorbitol. Antimicrob Agents Chemother.2001;45(1):166-9.

69. Tapiainen T, Renko M, Kontiokari T, Uhari M. Xylitol concentration in the saliva of children after chewing xylitol gum or consuming a xylitol mixture. Eur J Clin Microbiol Infect Dis.2002; 21: 53-55.

70. Tapiainen T, Renko M, Kontiokari T, Uhari M, Luotonen L. Xylitol administered only during respiratory infections failed to prevent acute otitis media. Pediatrics. 2002; 109: E19.

71. Tapiainen T, Sormunen R, Kaijalainen T, Kontiokari T, Ikaheimo I, Uhari M. Ultrastructure of Streptococcus pneumoniae after exposure to xylitol. Journal of Antimicrobial Chemotherapy. 2004; 54: 225-228.

72. Trahan L, Bareil M, Gauthier L, Vadeboncoeur C. Transport and phosphorylation of xylitol by a fructose phosphotransferase system in Streptococcus mutans. Caries Res. 1985; 19:53-63.

73. Trahan L. Xylitol: a review of its action on mutans streptococci and dental plaque - its clinical significance. Int Dent. 1995; 45:77-92.

74. Trindade CP. Efeito do uso de goma de mascar contendo xilitol sobre os niveis salivares de estreptococos do grupo mutans, sobre os genótipos de S. mutans e sobre a presença de amostras xilitol-tolerantes na saliva. [tese]. São Paulo (SP): Universidade de São Paulo; 2005.

75. Uhari M, Kontiokari T, Koskela M, Niemela M. Xylitol chewing gum in prevention of acute otitis media: double-blind randomised trial. BMJ.1996;313:1180-1184. 
76. Uhari M, Kontiokari T, Niemela M. A novel use of xylitol sugar in preventing acute otitis media. Pediatrics.1998;102 (4): 879-884.

77. Uhari M, Kontiokari $\mathrm{T}$, Tapiainen $\mathrm{T}$. Xylitol in preventing acute otitis media. Vaccine. 2001; 19: S144-S147. 
78. Gunay H, Bockhorn KD, Gunay Y, Geurtsen W. Effect on caries experience of a long-term preventive program for mothers and chindren starting during pregnancy. Clin Oral Invest. 1998; 2: 137-142. 
Abstract 


\begin{abstract}
Possible strategy for acute otitis media prevention: in vitro study of xylitol liberation in artificial saliva after application of varnishes in different concentrations
\end{abstract}

The aim of this study was to test xylitol release in artificial saliva along time after application of varnishes containing $10 \%$ and $20 \%$ xylitol. For this purpose, 15 block of bovine teeth were divided into three groups (Group 1-varnish 10\%; Group 2-varnish 20\%; Group 3-control). In sequence, each block was immersed in a microcentrifuge tube containing $500 \mu \mathrm{L}$ of artificial saliva. Saliva samples were collected and analyzed for xylitol in different times after varnishes application (1h, 8h, 12h, 16h, 24h, 48h e 72h). Data were analyzed by 2-way ANOVA and Tukey's test $(p<0.05)$. An interaction between group and time was observed (ANOVA, $F=1,486.25, p=0.0000$ ). Xylitol release was significantly higher for Group G2 in times $1 \mathrm{~h}(168.96 \mathrm{mg} / \mathrm{l})$ and $8 \mathrm{~h}(164.22 \mathrm{mg} / \mathrm{l})$ when compared with Group G1 (1h=63.42 $\mathrm{mg} / \mathrm{l}$ e $8 \mathrm{~h}=69.52 \mathrm{mg} / \mathrm{l})$. However, for the other periods, the sugar release was significantly higher in Group 1(56.92 mg/l; $49.70 \mathrm{mg} / \mathrm{l} ; 49.40 \mathrm{mg} / \mathrm{l} ; 55.52 \mathrm{mg} / \mathrm{l}$ and $32.66 \mathrm{mg} / \mathrm{l}$, respectively, for $12 \mathrm{~h}, 16 \mathrm{~h}$, $24 \mathrm{~h}, 48 \mathrm{~h}$ and $72 \mathrm{~h}$ ) when compared to Group G2 (29.90 mg/l; $18.52 \mathrm{mg} / \mathrm{l}$; $19.76 \mathrm{mg} / \mathrm{l} ; 24.20 \mathrm{mg} / \mathrm{l}$ and $12.72 \mathrm{mg} / \mathrm{l}$, respectively). In conclusion, the varnish containing $10 \%$ xylitol released sugar more slowly and for longer periods, characterizing a more homogeneous release.

Key words: Xylitol - prevention - acute otitis media - children 